\title{
Self-Healing Materials Systems: Overview of Major Approaches and Recent Developed Technologies
}

\author{
B. Aïssa, ${ }^{1,2}$ D. Therriault, ${ }^{2}$ E. Haddad, ${ }^{1}$ and W. Jamroz ${ }^{1}$ \\ ${ }^{1}$ Department of Smart Materials and Sensors for Space Missions, MPB Technologies Inc., 151 Hymus Boulevard Pointe Claire, \\ Montreal QC, Canada H9R 1E9 \\ ${ }^{2}$ Department of Mechanical Engineering, and Composites Center for Applied Research on Polymers QC (CREPEC), \\ École Polytechnique de Montréal, P.O. Box 6079, Montreal, Canada H3C 3A7 \\ Correspondence should be addressed to B. Aïssa, brahim.aissa@mpbc.ca
}

Received 2 September 2011; Accepted 25 November 2011

Academic Editor: S. Miyazaki

Copyright (๑) 2012 B. Aïssa et al. This is an open access article distributed under the Creative Commons Attribution License, which permits unrestricted use, distribution, and reproduction in any medium, provided the original work is properly cited.

The development of self-healing materials is now being considered for real engineering applications. Over the past few decades, there has been a huge interest in materials that can self-heal, as this property can increase materials lifetime, reduce replacement costs, and improve product safety. Self-healing systems can be made from a variety of polymers and metallic materials. This paper reviews the main technologies currently being developed, particularly on the thermosetting composite polymeric systems. An overview of various self-healing concepts over the past decade is then presented. Finally, a perspective on future self-healing approaches using this biomimetic technique is offered. The intention is to stimulate debate and reinforce the importance of a multidisciplinary approach in this exciting field.

\section{Introduction}

Polymers and structural composites are used in a variety of applications. However, these materials are susceptible to damage induced by mechanical, chemical, thermal, UV radiation, or a combination of these factors [1]. When polymer composites used as structural materials become damaged, there are only a few methods available to attempt to extend their functional lifetime. Ideal repair methods are ones that can be executed quickly and effectively directly on damaged site, eliminating thereby the need to remove a component for repair. However, the mode of damage must also be taken into consideration as repair strategies that work well for one mode might be completely useless for another. For example, matrix cracking can be repaired by sealing the crack with resin, where fibre breakage would require new fibres replacement or a fabric patch to achieve recovery of strength.

One of the earlier healing methods for fractured surfaces was "hot plate" welding, where polymer pieces were brought into contact above the glass transition temperature of the material, and this contact was maintained long enough for interdiffusion across the crack face to occur and restore strength to the material. It has been shown, however, that the location of the weld remains the weakest point in the material and thus the favourable site for future damage to occur [2]. For laminate composites, resin injection is often employed to repair damage in the form of delamination. This can be problematic, however, if the crack is not easily accessible for such an injection. For fibre breakage in a laminate composite, a reinforcing patch is often used to restore some of the strength to the material. Often, a reinforcing patch is used in conjunction with resin injection to restore the greatest amount of strength possible [3]. None of these methods of repair is an ideal solution to damage in a structural composite material. These methods are temporary solutions to prolong the lifetime of the material, and each of these repair strategies requires monitoring of the damage and manual intervention to enact the repair. This greatly increases the cost of the material by requiring regular maintenance and service.

Alternative healing strategies are therefore of great interest. Moreover, with polymers and composites being increasingly used in structural applications space, automobile, defence, and construction industries, several techniques have 


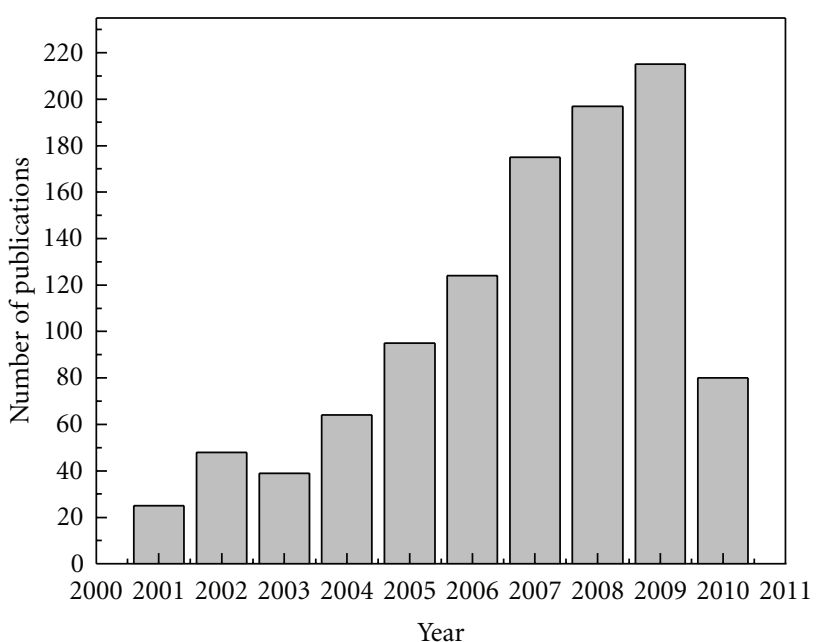

(a)

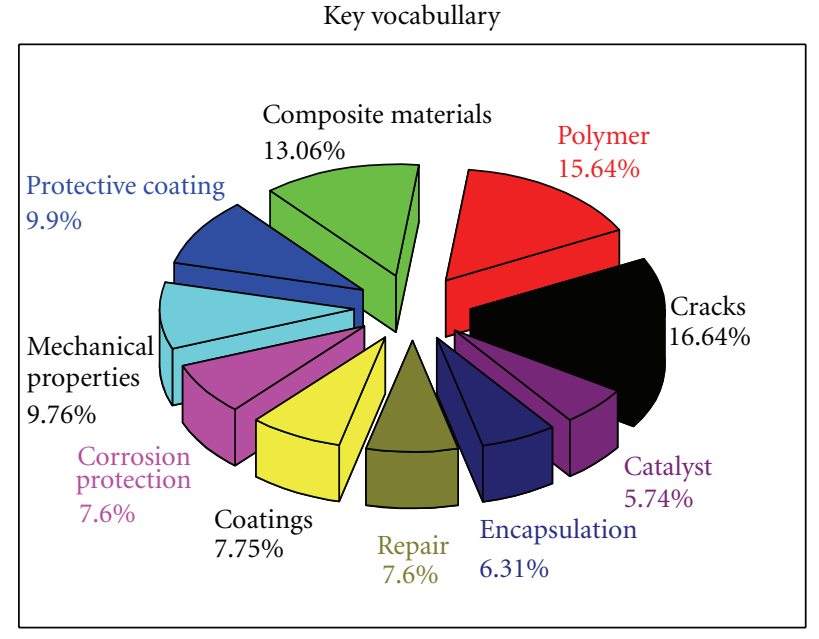

(b)

FIGURE 1: (a) Recent refereed publications related to the field of self healing materials, together with (b) their corresponding distribution of the employed key words vocabulary. All published languages were included. All document types, including journal and conference articles, report paper, conference proceeding, and monograph published chapters were recorded. Statistics are available from 2000 to August 2010 inclusively. Data were collected from Engineering Village web-based information service.

been developed and adopted by industries for repairing visible or detectable damages on the polymeric structures. However, these conventional repair methods are not effective, for example, for healing invisible microcracks within the structure during its service life. In response, the concept of "self-healing" polymeric materials was proposed in the 1980s [4] as a means of healing invisible microcracks for extending the working life and safety of the polymeric components. The publications in the topic by Dry and Sottos [5] in 1993 and then White et al. [6] in 2001 further inspired world interests in these materials [7]. Examples of such interests were demonstrated through US Air force [8] and European Space Agency [9] investments in self-healing polymers.

Conceptually, self-healing materials have the built-in capability to substantially recover their mechanical properties after damage. Such recovery can occur autonomously and/or be activated after an application of a specific stimulus (e.g., heat, radiation, pressure, etc.). As such, these materials are expected to contribute greatly to the safety and durability of polymeric components without the high costs of active monitoring or external repair. Throughout the development of this new range of smart materials, the mimicking of biological systems has been used as a source of inspiration (since most materials in nature are themselves self-healing composite materials) [10].

The number of publications dealing with various aspects of self-healing materials has increased markedly in recent years. Figure 1 shows how the number of refereed various articles in the self healing field has steadily increased since 2001, based on data collected from the Engineering Village web-based information service. Along with the increase in the number of publications in this area comes a need for a comprehensive review article, and the objective of this paper is to address this need.
In addition, the vast majority of the surveyed articles deal with polymer composites. Due to the large number of articles involved and the lack of electronic access to many conference proceedings, the emphasis of this paper is on the more accessible refereed journal articles. It was not practical to cover all of these articles, and, since a lot of articles had already been covered by previous related paper articles, an attempt was made to select representative articles in each of the relevant categories.

This paper briefly describes the traditional methods of repairing damage in the polymeric materials during the last decade. Table 1 provides summary of some developments and achieved performances. It can be seen that both thermoplastic and thermosetting materials were investigated for self healing, where the research interests have been more shifted to thermosetting-composite-based systems in recent years. We start by describing the methods for evaluating self healing efficiencies. We will then describe briefly some examples of different approaches proposed to heal the thermoplastic systems, and we follow by emphasising the preparation and characterization of the self healing of the thermosetting ones. We will take a short view on the self-healing coating for metallic structures systems, and we conclude by future research outlooks.

\section{Quantification of Healing Efficiency}

Healing of a polymeric material can refer to the recovery of properties such as fracture toughness, tensile strength, and surface smoothness. Due to the range of properties that are healed in these materials, it can be difficult to compare the extent of healing. Wool and O'Connor [32] proposed a basic method for describing the extent of healing in polymeric systems for a range of properties. This approach has been 
TABLE 1: Nonexhaustive main developments in self-healing polymer composites.

\begin{tabular}{|c|c|c|c|c|c|c|}
\hline Host material & Healing system & Stimulus & Best efficiency achieved & Healing condition & Test method & Ref. \\
\hline \multirow{6}{*}{$\begin{array}{l}\text { Thermosetting } \\
\text { and/or } \\
\text { thermosetting } \\
\text { composites }\end{array}$} & Hollow glass fibre & Mechanical & $93 \%$ & $\begin{array}{l}24 \text { hours at } \\
\text { ambient atm. }\end{array}$ & Flexure Strength & [11-20] \\
\hline & $\begin{array}{l}\text { Microencapsulation } \\
\text { approach }\end{array}$ & & 80-93\% & $\begin{array}{l}48 \mathrm{~h} \text { at } 80^{\circ} \mathrm{C} \\
24 \mathrm{~h} \text { at Ambient } \\
\text { then } 24 \mathrm{~h} \text { at } 80^{\circ} \mathrm{C}\end{array}$ & $\begin{array}{l}\text { Fatigue resistance } \\
\text { Fracture toughness } \\
\text { Tensile strength }\end{array}$ & {$[21,22]$} \\
\hline & Microvascular network & & $\begin{array}{c}60-70 \% \\
7-30 \text { cycles }\end{array}$ & $\begin{array}{l}12 \text { hours at } \\
\text { ambient atm. }\end{array}$ & Fracture toughness & {$[23,24]$} \\
\hline & Thermoplastic additives & & $30-100 \%$ & $\begin{array}{l}10 \mathrm{~min} \text { at } 120^{\circ} \mathrm{C} \\
1-2 \mathrm{~h} \text { at } 130-160^{\circ} \mathrm{C}\end{array}$ & $\begin{array}{l}\text { Flexure strength } \\
\text { Tensile strength } \\
\text { Impact strength }\end{array}$ & {$[25,26]$} \\
\hline & Shape memory alloy & Electrical & $77 \%$ & $\begin{array}{l}24 \text { hours at } \\
\text { ambient atm. }\end{array}$ & Fracture toughness & [27] \\
\hline & Carbon fibre & & $46 \%$ & $\begin{array}{l}1-20 \text { minutes at } \\
70-120^{\circ} \mathrm{C}\end{array}$ & Impact strength & {$[28]$} \\
\hline Elastomeric & Silicone rubber & Mechanical & $70-100 \%$ & $\begin{array}{l}48 \text { hours at } \\
\text { ambient atm. }\end{array}$ & Tear strength & [29] \\
\hline \multirow[t]{2}{*}{ Thermoplastic } & Molecular diffusion & & $100 \%$ & $5 \mathrm{~min}$. at $60^{\circ} \mathrm{C}$ & Fracture toughness & [30] \\
\hline & Photo-induced healing & Photo & $26 \%$ & $10 \mathrm{~min}$. at $100^{\circ} \mathrm{C}$ & Flexure strength & [31] \\
\hline
\end{tabular}

commonly adopted and has been used as the basis for method of comparing "healing efficiency" of different self healing polymeric systems.

There are different methods to effect healing that are applicable for each individual mode of damage as well as each unique damaged material. This makes quantifying the extent of healing within the material and comparing it to healing in other systems rather difficult. The susceptibility of a given material to fracture can be expressed in terms of the plane strain fracture toughness, $K_{\mathrm{IC}}$. It has become standard practice to assess the healing ability of a particular material by comparing the fracture toughness of the material both before and after healing. The healing efficiency is $\eta$,

$$
\eta(\%)=\frac{K_{\mathrm{IC}}^{\text {healed }}}{K_{\mathrm{IC}}^{\text {virgin }}} \times 100,
$$

where $K_{\mathrm{IC}}^{\mathrm{virgin}}$ is the fracture toughness of the virgin specimen and $K_{\mathrm{IC}}^{\text {healed }}$ is the fracture toughness of the healed specimen.

2.1. Self-Healing Efficiency Assessed by Fracture Test. For quasistatic fracture conditions healing efficiency is defined in terms of the recovery of fracture toughness. Healing evaluation begins with a virgin fracture test of an undamaged tapered double cantilever beam (TDCB) sample (Figure 2(a)). A precrack is introduced to sharpen the crack-tip, and loading of the specimen is increased until the crack propagates along the centerline of the sample until failure. The crack is then closed and allowed to heal at room temperature with no external intervention. After healing, the sample is loaded again until failure.
Crack healing efficiency, $\eta$, is defined as the ability of a healed sample to recover fracture toughness [32]:

$$
\eta=\frac{K_{\mathrm{IC}}^{\text {healed }}}{K_{\mathrm{IC}}^{\text {virgin }}}
$$

where $K_{\mathrm{IC}}^{\text {virgin }}$ and $K_{\mathrm{IC}}^{\text {healed }}$ represent the fracture toughness of the virgin and healed samples, respectively.

2.2. Self-Healing Efficiency Assessed by Fatigue Test. For dynamic fracture conditions, healing efficiency based on static fracture toughness recovery is no longer meaningful. Instead, the fatigue crack propagation behaviour of the self-healing epoxy was evaluated using the protocol outlined by Brown et al. who defined healing in terms of the life extension factor [33]:

$$
\eta_{d}=\frac{N_{\text {healed }}-N_{\text {control }}}{N}
$$

where $N_{\text {healed }}$ is the total number of cycles to failure for a selfhealing sample and $N_{\text {control }}$ is the total number of cycles to failure for a similar sample without healing.

Characterization of fatigue response is more complex than monotonic fracture because it depends on a number of factors such as the applied stress intensity range, the loading frequency, the ratio of applied stress intensity, the healing kinetics, and the rest periods employed [34]. The investigation considered successful healing as the recovery of stiffness lost due to damage induced by cyclic loading rather than changes in crack growth rate or absolute fatigue life. 


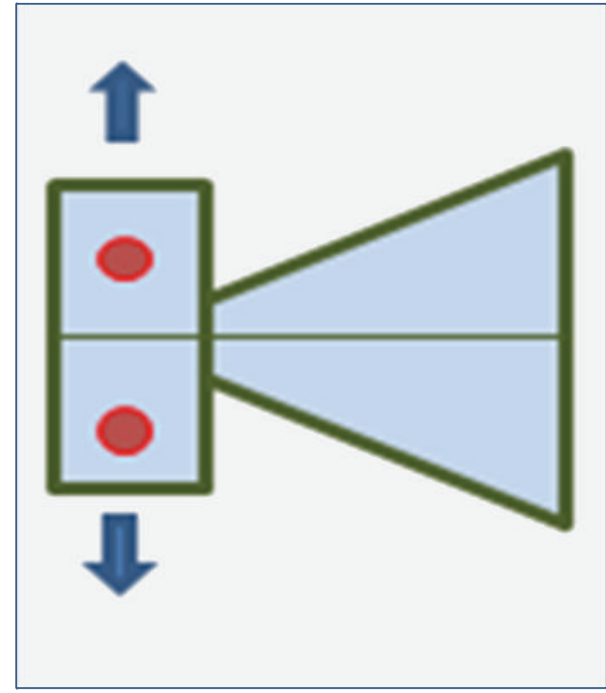

(a)

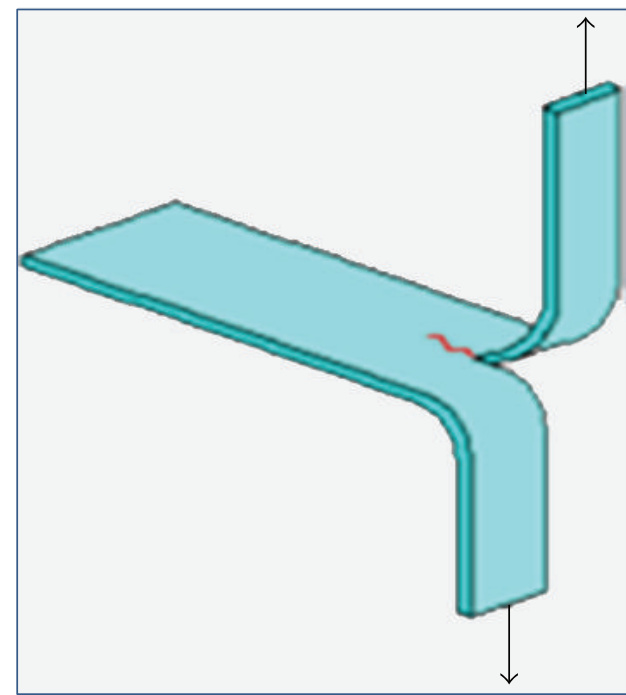

(b)

FIGURE 2: (a) Schematic of the TDCB-based fracture toughness and (b) tear protocols to evaluate healing performance.

2.3. Self-Healing Efficiency Assessed by Tear Test. For elastomeric self-healing material, the TDCB-based fracture toughness protocol to evaluate healing performance is inappropriate. Instead, the recovery of tear strength using a tear specimen is used to define healing efficiency, where

$$
\eta c=\frac{T_{\text {healed }}}{T_{\text {Virgin }}} .
$$

A tear test utilizes a rectangular coupon of material with a large axial precut that produces two loading arms. These arms are loaded in tension until the tear propagates through the rest of the specimen (Figure 2(b)). Healing evaluation begins with a virgin tear test of an undamaged sample. After failure, the sample loading arms are reregistered and healing occurs at room temperature with no external intervention. After healing, the tear sample is loaded again to failure. Using this test protocol, more than $70 \%$ recovery of the original tear strength was achieved in the PDMS (polydimethylsiloxane) system [29].

\section{Self-Healing of the Thermoplastic Materials}

Crack healing of thermoplastic polymers has been the subject of extensive research in the 1980s. The polymers investigated cover amorphous, semicrystalline, block copolymers, and fibre-reinforced composites. It has been discovered that when two pieces of the same polymer are brought into contact at a temperature above its glass transition $\left(T_{g}\right)$, the interface gradually disappears and the mechanical strength at the polymer-polymer interface increases as the crack heals due to molecular diffusion across the interface. For example, by using thermoplastics chain mobility with a minimal application of heat, Lin et al. [30] have studied crack healing in PMMA (poly(methyl methacrylate)) by methanol treatment from 40 to $60^{\circ} \mathrm{C}$. The authors have found that the tensile strength of PMMA treated by methanol can be fully recovered to that of the virgin material. On the other hand, another example of photo-induced self-healing in PMMA was reported by Chung et al. [31]. Mixture of photo linkable TCE (1,1,1-tris-(cinnamoyloxymethyl) Ethane) with UDME- (urethane-dimethacrylate-) and TEGDMA- (triethyleneglycol-dimethacrylate-) based monomers, blended with visible light photo-initiator CQ (camphorquinone), was polymerized into a hard and transparent film after its irradiation for $10 \mathrm{~min}$ with a $280 \mathrm{~nm}$ light source. The healing was shown to only occur upon exposure to the light of the correct wavelength, proving that the healing was light initiated. Healing efficiencies in flexural strength up to $14 \%$ and $26 \%$ were reported using light or a combination of light and heat $\left(100^{\circ} \mathrm{C}\right)$. However, healing was limited to the surfaces being exposed to light, meaning that internal cracks or thick substrates are unlikely to heal. In summary, self-healing of thermoplastic polymers can be achieved via a number of different mechanisms, including (i) recombination of chain ends, (ii) self-healing via reversible bond formation, (iii) living polymer approach, and (iv) self-healing by nanoparticles, in addition to the (v) molecular interdiffusion and (vi) photo-induced healing reported here. The processes are well known and have been well reported. A detailed description of these approaches can be found in [38].

\section{Self-Healing of Thermosetting Materials}

The search for self-healing thermosetting materials coincides with these materials being more and more widely used in numerous structural applications. These applications generally require rigid materials with a thermal stability that most thermoplastics do not possess. The rigidity and thermal stability of thermosetting comes from their cross-linked molecular structure, meaning that they do not possess the chain mobility so heavily utilized in the self-healing of thermoplastics. As a result of their different chemistry 
and molecular structure, the development of self-healing thermosetting has followed distinctly different routes.

The most common approaches for autonomic selfhealing of thermosetting-based materials involve incorporation of self-healing agents within a brittle vessel prior to addition of the vessels into the polymeric matrix. These vessels fracture upon loading of the polymer, releasing the low-viscosity self-healing agents to the damaged sites for subsequent curing and filling of the microcracks. The exact nature of the self-healing approach depends on (i) the nature and location of the damage, (ii) the type of self-healing resins, and (iii) the influence of the operational environment.

4.1. Hollow Glass Fibres Systems. The development of advanced fibre-reinforced polymers (FRPs) to achieve performance improvements in engineering structures focuses on the exploitation of the excellent specific strength and stiffness that they offer. However, the planar nature of an FRPs microstructure results in relatively poor performance under impact loading. This is an indication of their susceptibility to damage, which manifests mainly in the form of delamination. Hollow glass fibres have already been shown to improve structural performance of materials without creating sites of weakness within the composite $[39,40]$. These hollow fibres offer increased flexural rigidity and allow for greater custom tailoring of performance, by adjusting, for example, both the thickness of the walls and degree of hollowness [41, 42]. By using hollow glass fibres in these composites-alone or in conjunction with other reinforcing fibres it would be possible to not only gain the desired structural improvements, but to also introduce a reservoir suitable for the containment of a healing agent [40-43]. Upon mechanical stimulus (damage inducing fracture of the fibres), this agent would "bleed" into the damage site to initiate repair, not unlike biological selfhealing mechanisms $[11,12]$.

The first systems that have been investigated in 1996 and 1998 by Dry [13] and Li et al. [14], respectively, have validated that the proposed architecture for releasing chemicals from repair fibres was totally possible and then have used cyanoacrylate [13,14], ethyl cyanoacrylate [14], and methyl methacrylate $[15,16]$ as healing agents to heal cracks in concrete. This methodology was then transferred to polymer composite materials by Motuku et al. [17] in the late 1999. The healing agents contained within the glass fibres have been either a one-part adhesive, such as cyanoacrylate, or a two-part epoxy system, containing both a resin and a hardener, where either both are loaded in perpendicular fibres or one embedded into the matrix and the other inside fibres [18].

One of the initial challenges encountered when creating this type of self-healing systems is the development of a practical technique for filling the hollow glass fibres with repair agent. When approaching this problem, the dimensions of the glass fibre itself must be considered, including diameter, wall thickness, and fibre hollowness, as well as the viscosity and healing kinetics of the repair agent. Bleay et al. [18] were among the first to develop and implement a fibre filling method involving "capillary action" that is assisted by vacuum, which is now the main commonly used process. The chosen glass fibre should be also evaluated for its capacity to survive to the composite manufacturing process without breakage, while still possessing its ability to rupture during a damage event in order to release the required healing agent. Motuku et al. [17] have clearly determined that hollow glass fibres were best suited for this kind of application, as opposed to polymer tubes or those made of metal, which often did not provide controlled fracture upon impact damage.

In 2003, Hucker et al. [42] have shown that hollow glass fibres of a larger diameter offered an increased compressive strength, while giving larger volume of healing agent to be stored. The second important parameter to investigate was the capacity of the healing agent to adequately reach the site of damage and subsequently undergo healing. This mechanism will obviously depend upon the viscosity of the healing material, as well as the kinetics of the repair process. For example, the cyanoacrylate system studied by Bleay et al. [18] was shown, indeed, to restore mechanical strength to damaged specimens but also caused significant problems by curing upon contact with the opening of the fibre, which prevented the healing agent from reaching the site of damage in the sample. Various groups $[11,12,17,40]$ have then used liquid dyes inside the composites in order to serve as a damage detection mechanism, providing hence a visible indication of the damage site, while allowing a clear evaluation of the flow of healing agents to those sites.

Finally, the third parameter to optimize is the concentration of healing fibres within the matrix, their spacial distribution, and the final dimensions of the specimen, which have direct effects on the mechanical properties of the resulting composite material. As early demonstrated by Jang et al. [19] in 1990, the stacking sequence of the fibres within the composite plays a role in inhibiting plastic deformation and delamination and will also affect the response to an impact damage event. In order to maintain high mechanical properties, repair fibres need to be adequately spaced within the composite. Motuku et al. [17] have shown that thicker composites have shown better performances in healing studies. These parameters, however, will depend upon the dimension choice of fibre and chemical choice of the healing agent employed, and so optimization will depend on the specificities of the system being studied.

Until recently, the majority of the works done on selfhealing hollow fibre composites have focused on demonstrating the feasibility of such concept for self-repair and have reported qualitatively on the healing capacity of the studied systems. Recently, numerous works have reported quantitatively on mechanical properties associated with healing of the materials. The inclusion of hollow glass fibres into a composite system was shown by Jang et al. [19] and Trask and Bond [20] to give an initial reduction in the strength of the material, either by $16 \%$ in glass fibre reinforced polymer (GFRP) composites and by $8 \%$ in carbon-fibre reinforced polymer (CFRP) composites. These "self-repairing" composites were shown to recover $100 \%$ of the virgin strength for GFRP and $97 \%$ of the virgin strength for CFRP, but in both cases the composite materials were subjected to a heat treatment to aid in delivery of the resin to the damaged area as well as in curing of the healing agent. More 


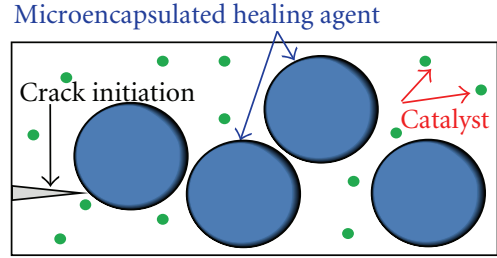

(i)

Healing agent

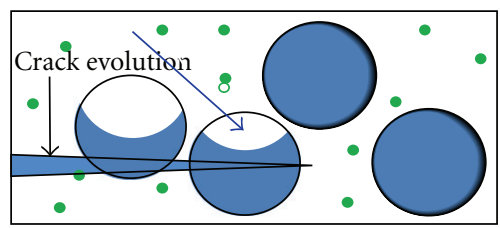

(ii)

Polymerized healing agent

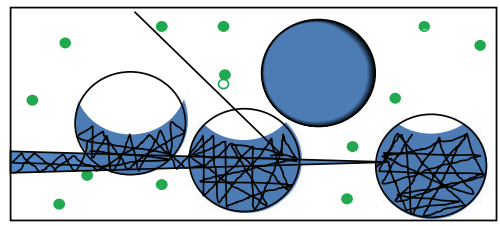

(iii)

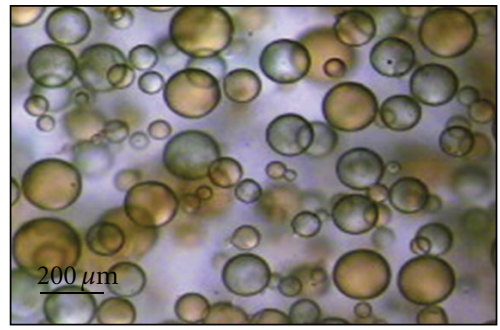

(iv)

(a)
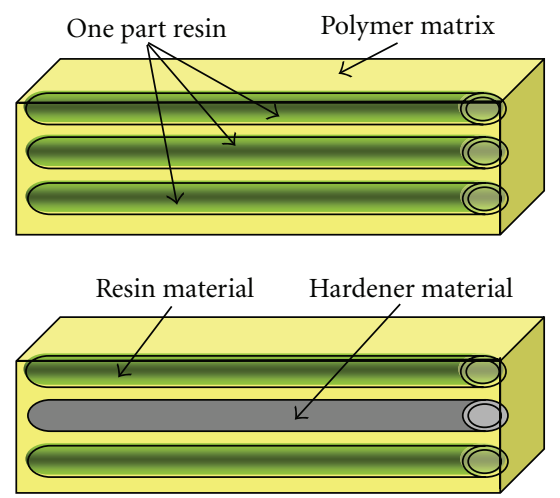

Resin material
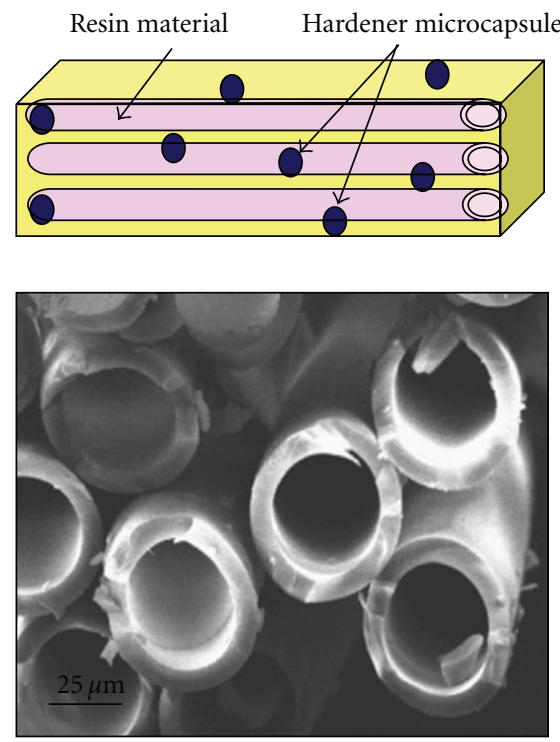

(b)

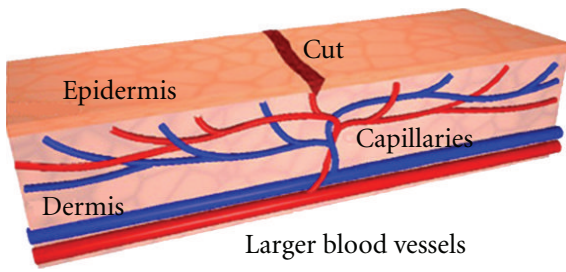

(i)

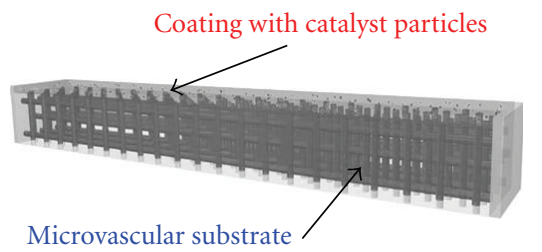

(ii)

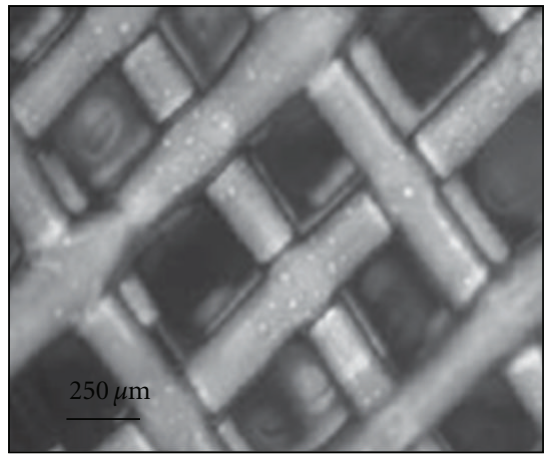

(iii)

(c)

FIGURE 3: (a) Autonomic healing concept incorporating encapsulated healing agent and embedded catalyst particles in a polymer matrix; (i) damage event causes crack formation in the matrix; (ii) crack ruptures the microcapsules, releasing liquid healing agent into crack plane; (iii) healing agent polymerizes upon contact with embedded catalyst, bonding crack closed; (iv) typical SEM image of the urea-formaldehyde microcapsules containing dicyclopentadiene prepared by emulsion in situ microencapsulation, adapted from [35]. (b) (i) Schematic diagram of smart repair concepts considered for hollow glass fiber polymer matrix composites. Use single-part, two-part resin and hardener, or resin with a catalyst/hardener. (ii) Typical scanning electron microscopy (SEM) image of the hollow glass fiber, adapted from [20]. (c) Biomimetic microvascular self-healing. (i) Schematic diagram of a capillary network in the dermis layer of skin with a cut in the epidermis layer (ii) Schematic diagram of the self-healing structure composed of a microvascular substrate and a brittle epoxy coating containing embedded catalyst, adapted from [23]. (iii) Optical image of the 3D microvascular network embedded in an epoxy matrix (Credit Photo D. Therriault).

recently, the work of Williams et al., [44] has considered the development of autonomic self-healing within a carbon fibre-reinforced polymer (CFRP), and has demonstrated the significant strength recovery $(>90 \%)$, which was possible when a resin filled hollow glass fibre system was distributed at specific interfaces within a laminate, minimising thereby the reduction in mechanical properties whilst maximising the efficiency of the healing event.

4.2. Systems Based on Microencapsulated Healing Agents. As above mentioned, and since the first report of the selfrepairing composites systems in the literature [6], conventional strategy was achieved by embedding a microencapsulated liquid healing agent and solid catalytic chemical materials within a polymer matrix. Hence, upon damageinduced cracking in the matrix, microcapsules are supposed to release their encapsulated liquid healing agent into the crack planes (Figure 3(a)). All the involved materials must be carefully engineered. For examples, encapsulation procedure must be chemically compatible with the reactive healing agent, and the liquid healing agent must not diffuse out of the capsule shell during its potentially long shelf-life. At the same time, the microcapsule walls must be resistant enough to processing conditions of the host composite, while maintaining excellent adhesion with the cured polymer matrix to ensure that the capsules rupture upon composite fracture.

Polymeric microcapsules are most often prepared via a miniemulsion polymerization technique, as described in 
the work of Asua [45]. The procedure involves the wellknown oil-in-water dispersions mechanism of the polymeric material. In the majority of self-healing composite systems that have been studied, the microcapsules are made by a ureaformaldehyde polymer, encapsulating DCPD as the liquid healing agent $[6,33,45-50]$ and/or epoxy resin $[48,51-$ 54]. In the case of DCPD, during the in situ polymerization process, urea and formaldehyde react in the water phase to form a low-molecular-weight prepolymer; when the weight of this prepolymer increased, it deposited at the DCPD-water interface. This urea-formaldehyde polymer becomes highly cross-linked and forms the microcapsule shell wall. The ureaformaldehyde prepolymer particles are then deposited on the surface of the microcapsules, providing a rough surface morphology that aids in the adhesion of the microcapsules with the polymer matrix during composite processing [55]. Moreover, composites using DCPD-filled ureaformaldehyde microcapsules have shown concrete healing ability in monotonic fracture and fatigue $[6,33,45-50]$.

4.2.1. Size and Material Microcapsules Effects. In 2003, Williams et al. [44] have reported that the microcapsules made in this oil-in-water in situ process have an average size of 10 $1000 \mu \mathrm{m}$ in diameter, with a smooth inner shell in the 160 $220 \mathrm{~nm}$ thick range, and fill content up to $83-92 \%$ liquid healing agent. The mechanical rupture of the microcapsule is the sine qua non condition event for the healing process. Hence, it is obviously important, therefore, to fabricate microcapsules with optimal mechanical properties and wall thickness. The relationship between the stiffness of the capsule and the one of the polymer matrix determines how the crack will propagate in the sample. In 2006, Keller and Sottos [56] have described how a capsule that has higher elastic modulus than the one of the polymer matrix material should create a stress field that tends to deflect cracks away from the capsule; a more compliant shell wall, on the other hand, will produce a stress field that attracts the crack towards the microcapsule.

The influence of microcapsule diameter and crack size on the performance of self-healing materials was also investigated in 2007 by Rule et al. [57]. They have used an epoxybased material containing embedded Grubbs' catalyst particles and microencapsulated DCPD. The amount of liquid that microcapsules could deliver to a crack face was shown to scale linearly with microcapsule diameter (and hence to the volume $^{1 / 3}$ ), for a given weight fraction of capsules. Moreover, the size of the microcapsule also plays a role in the performance of the system, in terms of the effect on toughness of the composite, and the nature of interface between microcapsule and polymer matrix. Based on these relationships, the size and weight fraction of microcapsules can be rationally chosen to give optimal healing of a given crack size.

However, as noted by Williams et al. [44], the shell wall thickness is largely independent of manufacturing parameters and is typically between 160 and $220 \mathrm{~nm}$ thick; nevertheless, slight adjustments can be made during the encapsulation procedure to alter the resulting microcapsules. The microcapsule size is controlled mainly via the rate of agitation during the encapsulation process; typical agitation rates reported by Williams et al. [44] range from 200 to $2000 \mathrm{rpm}$, with finer emulsions and therefore smaller diameter capsules being produced with increasing rates.

In 2004, Brown et al. have noted [46] that smaller microcapsules exhibit maximum toughening at lower concentrations; on the other hand, Rule et al. [57] have reported, in 2007, that specimens that contain larger microcapsules perform better than those with smaller microcapsules at the same weight fraction, presumably due to the amount of healing agent present in the samples. In the latter study, the best healing achieved was on a specimen containing $10 \mathrm{wt} . \%$ of $386 \mu \mathrm{m}$ capsules, which corresponds to $4.5 \mathrm{mg}$ of healing agent being delivered per unit crack area (assuming all capsules in the crack plane rupture). The amount of healing agent available for delivery to the crack plane was calculated based on the microcapsule size and weight fraction incorporated into the composite and was verified by comparing the data from these autonomously healing samples with that of samples, in which a known volume of healing agent was manually injected into the crack plane to initiate the healing process.

In the light of synthesizing smaller microcapsules that exhibit maximum toughening at lower concentrations, Blaiszik et al. [58] have reported in 2008 an in situ encapsulation method demonstrating over an order of magnitude size reduction for the preparation of urea-formaldehyde (UF) capsules filled with a DCPD healing agent, where capsules with diameters down to $220 \mathrm{~nm}$ were successfully achieved, using sonication techniques and an ultrahydrophobe solution to stabilize the DCPD droplets. The capsules were found to possess a uniform UF shell wall $(77 \mathrm{~nm}$ average thicknesses) and display good thermal stability. However, there are drawbacks with UF microcapsules: first, (i) the formation of agglomerated nanoparticles debris that could act as crack initiation sites within the host matrix, second, (ii) rough and porous wall surfaces formed by agglomerated nanoparticles that may reduce the adhesion between the microcapsules and matrix, and, finally, (iii) rubbery and thin capsule walls (160$220 \mathrm{~nm}$ [59]) that lead to the loss of core material during storage and cause handling difficulties during processing of the composites. In addition to UF microcapsules, melamineformaldehyde [60, 61] and polyurethane [62] shell wall materials were successfully used to prepare microcapsules of various healing materials. We note also the works of Liu et al., in 2009 [36], which have produced microcapsules for selfhealing applications with a melamine-urea-formaldehyde (MUF) polymer shell containing two different healing agent candidates, 5-ethylidene-2-norbornene (ENB) and ENB with $10 \mathrm{wt} . \%$ of a norbornene-based cross-linking agent (CL), by in situ polymerization in an oil-in-water emulsion (Figure 4). The microcapsules were found to be thermally stable up to $300^{\circ} \mathrm{C}$ and exhibited a 10 to $15 \%$ weight loss when isothermally held at $150^{\circ} \mathrm{C}$ for $2 \mathrm{~h}$. Overall, these MUF microcapsules exhibited superior properties compared to the urea-formaldehyde (UF) microcapsules used extensively for self-healing composites to date, and their manufacturing process is simpler than that made from UF. On the other hand, it is worthy reported at this level the innovative work of Mookhoek et al. [63], where microcapsules of 


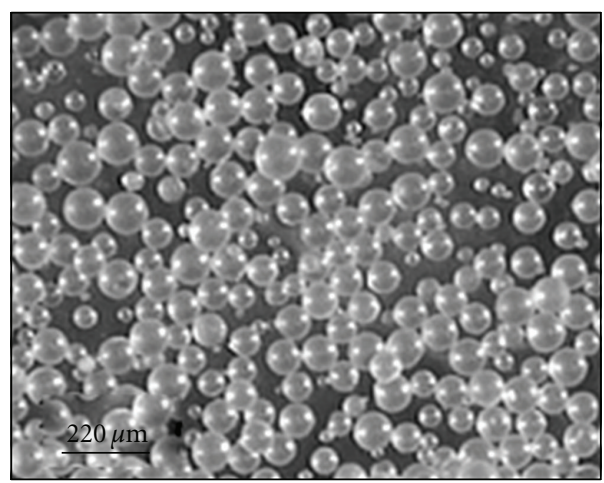

(a) ENB-Filled MUF microcapsules

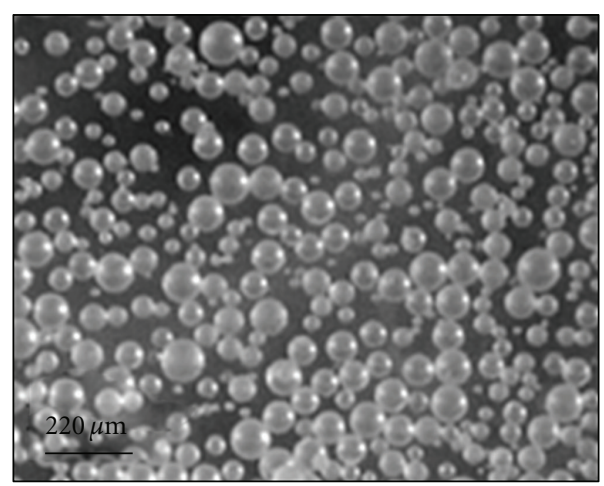

(b) ENB+CL-Filled MUF microcapsules

FIGURE 4: Optical microscopic images of ENB- and ENB + CL-filled MUF microcapsules with no debris formed $(M / U / F=3: 1: 8.5$, reaction temperature $\left.=86^{\circ} \mathrm{C}, \mathrm{rpm}=500\right)$. Copyright Macromol. Mater. Eng. [36].

size around $1.4 \mu \mathrm{m}$ dibutylphthalate-(DBP-) filled urea-formaldehyde (UF) were used as pickering stabilizers to create larger $(\sim 140 \mu \mathrm{m})$ microcapsules containing a second liquid phase of DCPD. The binary microcapsules were made by encapsulating the dispersed DCPD liquid (stabilized with the UF (DBP) microcapsules in water), via an isocyanate-alcohol interfacial polymerization reaction.

Various applications have been attempted with more or less success. Microcapsules have been used in the paper industry for a range of different purposes, for example, in self-copying carbonless copy paper [64], and in the food and packaging industries for applications such as control of aroma release and temperature or humidity indicators [38]. Other possible applications might include encapsulation of antimicrobial agents or scavengers in active packaging. Recently, Andersson et al. [65] have developed microcapsules with a hydrophobic core surrounded by a hydrophobically modified polysaccharide membrane in aqueous suspension, to obtain capsules fulfilling both the criteria of small capsule size and reasonably high solids content to match the requirements set on surface treatment of paperboard for enhancement of packaging functionality, and they have shown a reduced tendency for deteriorated barrier properties and local termination of cracks formed upon creasing.

4.2.2. Fatigue Cracks Retardation. To retard the growth of fatigue cracks, shape-memory alloy (SMA) wires are well suited to this application since they exhibit a thermoelastic martensitic phase transformation, contracting above their transformation temperature and exerting large recovery stresses of up to $800 \mathrm{MPa}$, when constrained at both ends [66-68]. Moreover, Rogers et al. [69] have shown that, when an SMA wire is embedded within an epoxy matrix, the full recovery force acts at the free edges of the component. Therefore, an SMA wire bridging a crack should induce a large closure force on the crack. Indeed, Kirkby et al. [27] have reported on the self-healing polymers with embedded shape-memory alloy (SMA) wires, where the addition of SMA wires shows improvements of healed peak fracture loads by up to $160 \%$ (comparatively with specimen without SMA), approaching the performance of the virgin material.
Moreover, the repairs can be achieved with reduced amounts of healing agent. The improvements in performance were attributed mainly to the crack closure, which reduces the total crack volume and increases the crack fill factor for a given amount of healing agent and the heating of the healing agent during polymerization, which increases the degree of cure of the polymerized healing agent.

4.2.3. Delaminating Substrate. Because of their excellent inplane properties and high specific strength, fibre-reinforced composites with polymeric matrices have found many uses in structural applications. Despite this success, they are particularly prone to damage from out-of-plane impact events. Although fibre damage is usually localized at the site of impact, matrix damage in the form of delaminations and transverse cracks can be more widespread. Delaminations, in particular, pose a serious issue because they can significantly reduce compressive strength [70-73] and grow in response to fatigue loading $[70,74,75]$. In addition to this problem, impact damage can be subsurface or barely visible, necessitating the use of expensive and time-consuming nondestructive inspection [70]. Once damage is located, there are many repair techniques that have been proposed and/or are currently practiced [76-79]. As we have mentioned, most solutions rely on resin infiltration of delaminations or composite patches, to provide load transfer across the damaged region. In cases of severe damage, damaged regions are removed and replaced with new composite material that is bonded or cocured to the original one [76]. These repair techniques are generally time-consuming complicated and require unhindered access. Recently, Patel et al. [80] have studied the autonomic self-healing of impact damage in composite materials by using a microencapsulated healing agent (DCPD liquid healing agent and paraffin wax microspheres containing $10 \mathrm{wt}$ \% Grubbs' catalyst), which has been successfully incorporated in a woven S2-glass-reinforced epoxy composite. Low velocity impact tests reveal that the selfhealing composite panels are able to autonomically repair impact damage. Fluorescent labelling of damage combined with image processing shows that total crack length per imaged cross-section is reduced by $51 \%$ after self-healing. 
TABLE 2: Literature summary of self-healing chemicals investigated for the microencapsulation approach. Adapted from [34].

\begin{tabular}{lllc}
\hline Self-healing agent & Catalyst & Self-healing reaction & Reference \\
\hline Dicyclopentadiene (DCPD) & $\begin{array}{l}\text { Bis(tricyclohexylphosphene) benzylidine } \\
\text { ruthenium (IV) dichloride (Grubbs' catalyst) }\end{array}$ & $\begin{array}{l}\text { Ring-opening metathesis } \\
\text { polymerization }\end{array}$ & $\begin{array}{c}{[6,21,22,34,46,} \\
47,49,83-90]\end{array}$ \\
\hline 5-Ethylidene-2-norbornene (ENB) & $\begin{array}{l}\text { Bis(tricyclohexylphosphene) benzylidine } \\
\text { ruthenium (IV) dichloride (Grubbs' catalyst) }\end{array}$ & $\begin{array}{l}\text { Ring-opening metathesis } \\
\text { polymerization }\end{array}$ & {$[86]$} \\
\hline $\begin{array}{l}\text { DCPD/ENB blends } \\
\begin{array}{l}\text { Mixture of hydroxyl end functionalised } \\
\text { Polydimethylsiloxane (HOPMDS) and } \\
\text { Polydiethoxysiloxane (PDES) }\end{array}\end{array}$ & $\begin{array}{l}\text { Bis(tricyclohexylphosphene) benzylidine } \\
\text { ruthenium (IV) dichloride (Grubbs' catalyst) }\end{array}$ & $\begin{array}{l}\text { Ring-opening metathesis } \\
\text { polymerization }\end{array}$ & {$[87]$} \\
\hline Epoxy & Di-n-butyltin dilaurate & Polycondensation & {$[91]$} \\
\hline Styrene-based system & Amine & Polycondensation & {$[48,51,92]$} \\
\hline
\end{tabular}

On the other hand, flexible, laminated, self-healing bladder material was investigated to mediate the impact of small tears and punctures. Previous attempts at healing puncture damage have focused on ionomers [81]. A self-healing response in ionomers initiates through the transfer of energy from a fast moving projectile, which is typically a few millimetres in diameter. Frictional heating of the material from the passage of the projectile leads to a reorientation of the polymer chains in the ionomer. This rearrangement can, under some conditions, seal the hole generated by the projectile. However, this healing occurs only when the damaged area is heated to near the melt temperature of the material [81]. In 2009, Beiermann et al. [82] have manufactured a three-layer flexible self-healing materials, capable of repairing puncture damage. The used material consisted of three layers: a poly(dimethyl siloxane) (PDMS) composite, embedded with a self-healing microcapsule system, sandwiched between two layers of poly(urethane)-coated nylon. A protocol was established in which samples were damaged using a hypodermic needle or a razor blade, and a successful heal was defined as the ability to reseal the damage to withstand a pressure differential across the laminate of $103 \mathrm{kPa}$ (at $1 \mathrm{~atm}$.). Healing was shown to vary significantly with microcapsule size, with the maximum healing success rate $(100 \%$ successfully healed) occurring in samples with $220 \mu \mathrm{m}$ in diameter microcapsules. Additionally, healing was found to increase with composite layer thickness, and decrease with increasing puncture size.

Finally, fracture testing, in the form of single-edge notched bending tests, has shown a healing efficiency of $111 \%$, when the concentration of microcapsules and latent hardener were optimized. Some preliminary tests on epoxybased fabric laminates containing this self-healing system demonstrated a $68 \%$ recovery of virgin inter-laminar fracture toughness. Yuan et al. [52] have reported another promising combination of healing agent and catalyst for selfhealing polymer composites. The healing agent, consisting of a mixture of diglycidyl ether of bisphenol A (DGEBPA) along with a catalyst made from 1-butyl glycidyl ether (BGE), was stored in poly(urea-formaldehyde) (PUF) microcapsules, which were prepared by the conventional oil inwater emulsion process. This process of preparing the PUF microcapsules has promoted long shelf-life and good chemical stability at temperatures below $238^{\circ} \mathrm{C}$. This system is still in the early developmental stages, and its self healing efficiency within a composite material is yet to be tested.

In sum, the microencapsulation approach is by far the most studied self-healing concept in recent years. Table 2 summarizes the type of self-healing systems investigated in the literature, and it is noticed that the self-healing system based on living ring-opening metathesis polymerization (ROMP) has attracted most of the research attention. There are some obvious similarities between the microencapsulation and hollow fibre approaches, but the use of microcapsules alleviates the manufacturing problems experienced in the hollow fibre approach. The microencapsulation approach is also potentially applicable to other brittle material systems such as ceramics and glasses [93]. On the other hand, the most successful and extensively investigated selfhealing system comprises the ROMP of dicyclopentadiene (DCPD) with Grubbs' catalyst. The synthesis and characterization of the DCPD/Grubbs catalyst system have recently been papered [94], and their use as a self-healing agent has been widely reported as we mentioned here above. This system supposedly provides a number of advantages such as long shelf-life, low monomer viscosity and volatility, and completion of polymerization at ambient conditions in several minute. Further attempts were made to improve the performance of the self-healing system by replacing DCPD with 5-ethylidene-2-norbornene (ENB) [86] or blending ENB with DCPD [87]. Microencapsulation of ENB was also achieved by in situ polymerization of urea and formaldehyde. This system was supposed to overcome some of the limitations of the DCPD including the low melting point and the need to use a large amount of catalysts. It is recognized that DCPD is capable of forming a cross-linked structure with high toughness and strength $[38,95,96]$ whilst ENB polymerizes to a linear chain structure and may possess inferior mechanical properties. However, ENB is known to react faster in the presence of a lower amount of Grubbs' catalyst, has no melting point, and produces a resin with a higher $T_{g}$ $[38,86]$. Hence, a blend of DCPD with ENB was believed to provide a more reactive healing system with acceptable mechanical properties, making it more suitable for practical 
use. Cho et al. [91] chose to develop a completely different healing system using di-n-butyltin dilaurate (DBTL) as the catalyst and a mixture of HOPDMS (hydroxyl end-functionalized polydimethyl-siloxane) and PDES (polydiethoxysiloxane) as the healing agent. The polycondensation of HOPDMS with PDES is alleged to occur rapidly at room temperature in the presence of the organotin catalyst even in open air $[97,98]$.

4.3. Three-Dimensional Microchannel Structure Systems. As reported by the paper of Murphy and Wudl [55], complex microvascular networks are widely observed in biological systems, such as leaf venation [99-102] and blood vascularisation [103-105]. Indeed, in the latter case, the human circulatory system is comprised of vessels of varying diameter and length: arteries, veins, and capillaries. These vessels function together in a branched system to supply blood to all points in the body simultaneously. However, due to their complex architecture, replication of these microvascular systems remains a significant challenge for those pursuing synthetic analogs. As outlined in 2006 by Stroock and Cabodi [106], these microvascular networks can be created via soft lithographic methods [107-109], in which all microchannels can be fabricated at the same time, laser ablation $[110,111]$ or direct write methods [112], which are more suited for building three-dimensional (3D) micro-channel structures (Figure 3(c)). One of the main advantages of those systems comparatively to both the hollow fibre and microcapsule systems is their ability to heal the same location in the material more than once. Indeed, often, a second fracture event will occur along the plane of the initial crack. By providing a material with a quasicontinuous flow of healing agent, numerous healing cycles can be achieved.

In 2007, Toohey et al. [23] have published one of the first of these types of composite materials. Authors have reported self-healing systems that are capable of autonomously repairing repeated damage events. The reported system which bio-inspired coating-substrate design delivered healing agent to cracks in a polymer coating via a three-dimensional microvascular network [112] that was first embedded into the substrate. This system utilized the healing combination of liquid DCPD as the healing agent and solid Grubbs' catalyst to initiate ROMP polymerization of the DCPD. In the reported work, the catalyst was incorporated into a $700 \mu \mathrm{m}$ thick epoxy coating that was applied to the top surface of the microvascular substrate, and the $200 \mu \mathrm{m}$ wide channels were successfully filled with DCPD and then sealed. This system achieved a peak healing efficiency up to $70 \%$ with $10 \mathrm{wt} . \%$ catalyst in the top coating and was able to demonstrate healing for up to seven cycles. It is important to mention that the amount of catalyst in the top epoxy layer did not affect the average healing efficiency per cycle, but rather limited how many cycles of testing and healing could be performed successfully. Indeed, once all of the catalyst has been used, healing ceased due to depletion of catalyst in the crack plane, even with a continuous supply of monomer.

To overcome this limitation, in 2009, Toohey et al. [113] have modified their design by photolithographically patterning four isolated regions within the embedded microvascular network. Authors have reported the repeated healing of crack damage in a polymeric coating through delivery of two-part epoxy, healing chemistry via multiple microvascular networks embedded in isolation within a polymeric substrate. They first have created a continuous, interconnected microvascular network using the direct-write method. Second, they then have isolated multiple networks by infilling the network with a phot-ocurable resin and selectively photopolymerizing thin parallel sections of these resin-filled microchannels. Epoxy resin and amine-based curing agents were transported to the crack plane through two sets of independent vascular networks embedded within a ductile polymer substrate beneath the coating. The two reactive components remain isolated and stable in the vascular networks until crack formation occurs in the coating under a mechanical load. Both healing components were wicked by capillary forces into the crack plane, where they react and effectively bond the crack faces closed. Several epoxy and curing agent combinations were evaluated for their suitability in microvascular-based autonomic systems, and healing efficiencies of over $60 \%$ for up to 16 intermittent healing events out of 23 cycles were successfully achieved.

In a related effort, Williams et al. have published their version of a microvascular network containing mechanically stimulated healable material, in the form of sandwich structure composite configurations that contain either single [24] or dual [114] fluidic networks. In the single network design, sandwich structures use high-performing skin materials, such as glass or carbon fibre composites, separated by a lightweight core to obtain a material with very high specific flexural stiffness. A vascular network incorporated into a sandwich structure would address the larger damage volume expected of these systems, as well as allowing for multiple healing events to occur. Samples were fabricated with channels containing a healing agent, which had a negligible effect on the mechanical properties of the composite. Rupture of the vessels released the healing fluid, filling the void that formed as a result of impact damage on the sample. Initial tests were run on samples containing premixed resin and hardener, to demonstrate the healing capability of the system. Indeed, these samples have shown consistent and complete recovery of compressive stress at failure after impact damage. In their dual network design, significant recovery was also observed when samples were infiltrated with pressurized unmixed dual fluids [114].

\section{Self-Healing Coating Systems for Metallic Structures}

The large economic impact of corrosion of metallic structures is a very important issue all over the world. Generally, rapid field-specific testing is done when material failure is observed. Despite intense research and developments in corrosion protection coatings of metals and alloys, the real-world performance results are not always satisfactory. Furthermore, development of all around coatings to protect and prolong service life of the infrastructure is still a big challenge, owing to wide variations in environmental 
conditions. Therefore, in order to improve the equipment service prediction capabilities of infrastructure, it is indispensable to develop new state-of-the-art smart/selfhealing coating formulations for corrosion inhibition. In this context, autonomic healing materials respond without external intervention to environmental stimuli and have great potential for advanced engineering systems $[6,11$, $12,23,29,46,53,85,91,115-126]$. Self-healing coatings, which autonomically repair and prevent corrosion of the underlying substrate, are of particular interest. Notably, the worldwide cost of corrosion has been estimated to be nearly $\$ 300$ billion per year [127]. Recent studies on self-healing polymers have demonstrated repair of bulk mechanical damage as well as dramatic increases in the fatigue life. The majority of these systems, however, have serious chemical and mechanical limitations, preventing their use as coatings. Polymer coating systems are classically applied on a metal surface to provide a dense barrier against the corrosive species. Cathodic protection is also used for many applications, in addition to coatings, to protect the metal structures from corrosive attack when the coating is damaged. Hence, self-healing coatings are considered as an alternative route for efficient anticorrosion protection while maintaining a low demand in cathodic protection.

Cho et al. [128] have explored two self-healing coating approaches, starting from the siloxane-based materials system. In the first approach, the catalyst was microencapsulated and the siloxanes were present as phase-separated droplets. On the second process, the siloxanes were also encapsulated and dispersed in the coating matrix. Encapsulation of both phases (the catalyst and the healing agent) is advantageous in cases where the matrix can react with the healing agent. In the other hand, Aramaki $[129,130]$ has prepared a highly protective and self-healing film of organosiloxane polymer containing sodium silicate and cerium nitrate, on a zinc electrode previously treated in a $\mathrm{Ce}\left(\mathrm{NO}_{3}\right)_{3}$ solution. Self-healing mechanism of the film was investigated after it was scratched and immersed in the $\mathrm{NaCl}$ solution for several hours, where a passive film has been found to be formed on the scratched surface, resulting in suppression of pitting corrosion at the scratch. More recently, the same group $[131,132]$ has prepared an ultrathin 2D polymer coating, on a passivated iron electrode, which was subsequently healed in $\mathrm{NaNO}_{3}$. Thus done, localized corrosion was markedly prevented by coverage with the polymer coating and the healing treatment in $0.1 \mathrm{M}-\mathrm{NaNO}_{3}$. Indeed, prominent protection of iron from corrosion in $0.1 \mathrm{M}-\mathrm{NaCl}$ was observed. The protective efficiencies were found to be extremely high in certain cases, where more than 99.9\% before the passive film was broken down.

The development of effective corrosioninhibitor coatings for prevention of corrosioninitiation and suppression of galvanic activity of metals and alloys has always been a challenging problem. Recent concerted efforts of researchers at US Army Engineering Research and Development Center at the Construction Engineering Research Laboratory (ERDC-CERL) and at other facilities [133, 134] have led to development of self-healing corrosion inhibitors, to reduce and/or prevent corrosion of metal hardware. Previously, heavy metal-based epoxy primer pretreatment systems [135], including quaternary ammonium salt-based and multifunctional microcapsulated corrosioninhibitor system [133-135], have demonstrated corrosion protection performance of metals and alloys. These studies have demonstrated that the scribe or damaged film area on otherwise corroded panels experienced little lifting and blisters, among others, of the film because of the presence of microcapsules at the scribes. Mehta and Bogere [136] have evaluated the smart/self-healing microcapsulated inhibitor incorporated in epoxy primer before painting on a steel surface, for its corrosion protection effectiveness on exposure to ASTM (American Society for Testing and Materials) D 5894 electrolyte in laboratory and natural tropical seashore environment. The "healant" inhibitor was industrial custom made. Their results have indicated that the active components in ruptured embedded inhibitor microcapsules were released into an inflicted scribe primer and topcoat film on steel surface on exposure to inhibit development of an electrochemical cell. Undamaged surface film of the test and control specimens exposed in the environments demonstrated excellent corrosion-inhibition performance as reflected by both visual inspection and electrochemical impedance spectroscopy experimental data.

All of those reported results should provide an understanding of the fundamental material-property relationships of smart inhibitor coatings and, thus, should facilitate the development of optimized paint compositions in order to extend the useful service life of steel infrastructure applications.

\section{Futures Outlooks}

In summary, we finally know that the material degradation can occur for a wide variety of reasons, such as fatigue loadings, thermal effects, and corrosion, or, more in general, for environmental effects of all kinds. However, the materials durability is probably one of the main challenges encountered today for structural as well as coating applications. As the materials failure normally starts at the nanoscale level and is then amplified to the micro- up to the macro-scale level until catastrophic failure occurs, the ideal solution would be to block and/or eliminate damage as it occurs at the nano/microscale and restore the original material properties.

We have seen that the healing process can be initiated by means of an external source of energy (stimuli), as it was shown in the case of a bullet penetration [137] where the ballistic impact caused local heating of the material allowing self-healing of ionomers, or in the case of self-healing paintings used in the automotive industry. In the latter case, small scratches can be restored by solar heating [138]. Single cracks formed in PMMA specimens at room temperature were also shown to be completely restored above the glass transition temperature $[4,139,140]$. The presence of noncovalent hydrogen bonds [141] in mechanosensitive polymers can allow a rearrangement of principal chemical bonds so that they can be used for self-healing. Numerical studies have also shown that nanoscopic gel particles, which are interconnected in a macroscopic network by means of 


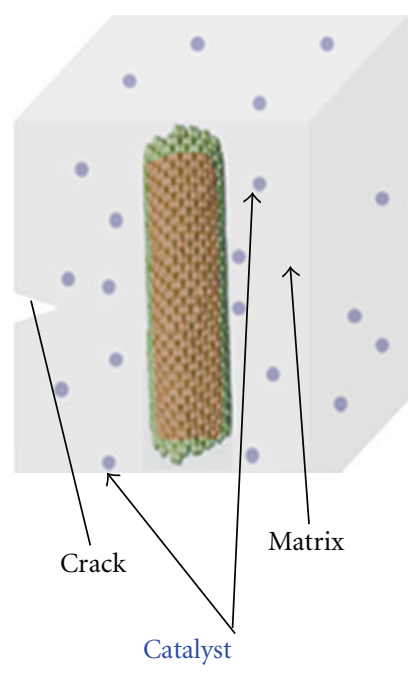

(a)

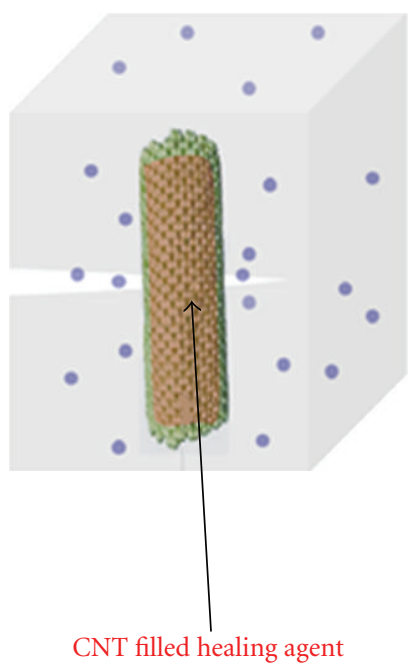

(b)

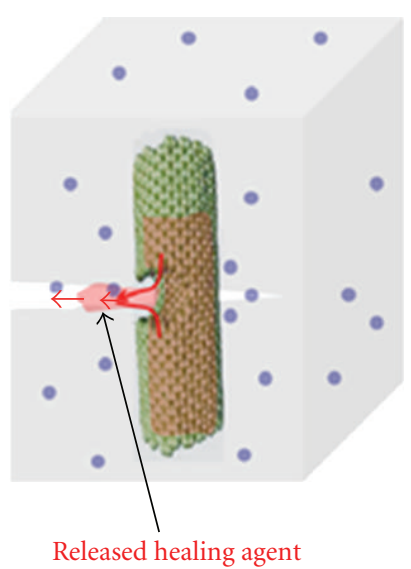

(c)

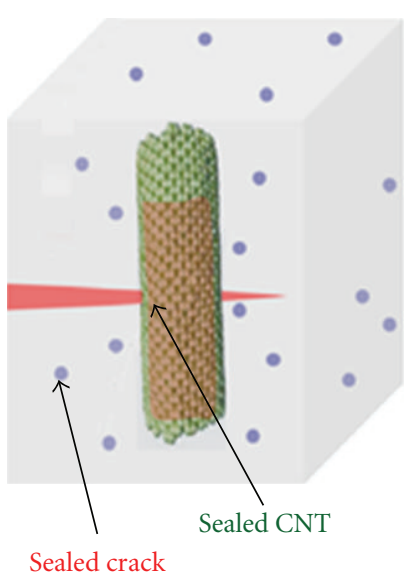

(d)

Figure 5: Concept of the self-healing process using carbon nanotubes. Adapted from [37].

stable and labile bonds, have the potential to be used in selfhealing applications.

To date, all the employed techniques are, however, limited by the container size. Containers should be in the nanoscale range since larger ones could lead to large hollow cavities, that could compromise the mechanical properties of the hosting structural material, and/or the passive protective properties of the coating material [25]. Moreover, up to date, advanced materials are designed to be either tough or selfhealing, but typically not both. It would be ideal to have a material which could be at the same time tougher and self-repairable, and this is still not possible with current technologies.

Carbon nanotubes (CNTs) are considered to be an ideal filler material for mechanical reinforcement as well as ideal molecular storage devices. This is due to the fact that CNTs are very small, thus they have an extremely large interfacial area. CNTs have interesting mechanical and chemical properties and have a hollow tubular structure. Polymer/CNTs composites (e.g., [142]) have already shown many promising results, and various materials, such as hydrogen $\left(\mathrm{H}_{2}\right)$ [143], metal and/or metal carbide [144], $\mathrm{C}_{60}$ [145], $\mathrm{CH}_{4}$ [146] and DNA [147], have been successfully inserted inside CNT. Although a great deal of work has been done with CNTs as self-storage devices, CNTs have not been yet investigated as nanoreservoirs for self-healing applications.

The main challenges related with this application are how to insert molecules into the carbon nanotubes, whether crack can form on the sidewall of a carbon nanotube during its propagation, and if the healing agent will come out of the carbon nanotube when the crack forms. In this avenue, recently, Lanzara et al. [37] have investigated the use of CNTs as nanoreservoirs for automatic repairing applications, through a molecular dynamics (MD) study with particular focus on the CNTs capacity of delivering a healing agent. Authors have shown, interestedly, that the CNTs were not only able to carry the catalytic healing agent for local repair but also can simultaneously play the role of filler material for mechanical reinforcement prior and after the delivery of the active material (Figure 5).

\section{Conclusions}

In conclusion, we have briefly presented a series of recent results related to the various self-healing concepts and systems. Research into self-healing materials is an active and exciting field, with an increasing number of research papers being published every year. From the studies on healing in concrete structures via embedded glass fibres to the more recent work on healing using shape memory alloy wires in a polymer composite, and/or the use of multidimensional microvascular network for the healing applications, the different avenues being explored to achieve the common end goal of prolonged functional lifetimes for composite structural materials are astounding. Beyond a strong interest of both academic and commercial researchers in the hollow fibre and microencapsulation approaches to self-healing polymer development, new types of self healing technology have been emerging at an increasing rate over the last decade. Indeed, in recent years, interesting perspectives have opened for the design of innovative self-healing nanosystems. Computer simulations have provided useful indications for directing the efforts of scientists toward the fabrication of repairing systems.

\section{Acknowledgments}

The authors would like to gratefully acknowledge the financial assistance of the Canadian Space Agency for this work, the Natural Science and Engineering Research Council (NSERC) of Canada, and the Fonds Québécois de la Recherche sur la Nature et les Technologies (FQRNT). 


\section{References}

[1] C. B. Bucknall, I. C. Drinkwater, and G. R. Smith, "Hot plate welding of plastics: factors affecting weld strength," Polymer Engineering and Science, vol. 20, no. 6, pp. 432-440, 1980.

[2] D. Liu, C. Y. Lee, and X. Lu, "Repairability of impact-induced damage in SMC composites," Journal of Composite Materials, vol. 27, no. 13, pp. 1257-1271, 1993.

[3] T. Osswald and G. Menges, "Failure and damage of polymers," in Materials Science of Polymers for Engineers, T. Osswald and G. Menges, Eds., p. 447, Hanser Publishers, Munich, Germany, 2003.

[4] K. Jud, H. H. Kausch, and J. G. Williams, "Fracture mechanics studies of crack healing and welding of polymers," Journal of Materials Science, vol. 16, no. 1, pp. 204-210, 1981.

[5] C. M. Dry and N. R. Sottos, "Passive smart self-repair in polymer matrix composite materials," in Proceedings of the Conference on Recent Advances in Adaptive and Sensory Materials and Their Applications, pp. 438-444, Technomic, Virginia, USA, 1993.

[6] S. R. White, N. R. Sottos, P. H. Geubelle et al., "Autonomic healing of polymer composites," Nature, vol. 409, no. 6822, pp. 794-797, 2001.

[7] A. J. M. Schmets and S. van der Zwaag, "The role of the aging temperature on the self healing kinetics in an underaged AA2024 aluminium alloy," in Proceedings of the 1st International Conference on Self Healing Materials, vol. 100 of Springer Series in Materials Science, pp. 1-7, Springer, Noordwijk, Netherlands, April 2007.

[8] H. C. Carlson and K. C. Goretta, "Basic materials research programs at the U.S. Air Force Office of Scientific Research," Materials Science and Engineering B: Solid-State Materials for Advanced Technology, vol. 132, no. 1-2, pp. 2-7, 2006.

[9] C. Semprimosching, "Enabling self-healing apabilities-a small step to bio-mimetic materials," Tech. Rep. 4476, European Space Agency Materials, Noordwijk, The Netherlands, 2006.

[10] S. Varghese, A. Lele, and R. Mashelkar, "Metal-ion-mediated healing of gels," Journal of Polymer Science, Part A: Polymer Chemistry, vol. 44, no. 1, pp. 666-670, 2006.

[11] J. W. C. Pang and I. P. Bond, "A hollow fibre reinforced polymer composite encompassing self-healing and enhanced damage visibility," Composites Science and Technology, vol. 65, no. 11-12, pp. 1791-1799, 2005.

[12] J. W. C. Pang and I. P. Bond, "'Bleeding composites"damage detection and self-repair using a biomimetic approach," Composites Part A: Applied Science and Manufacturing, vol. 36, no. 2, pp. 183-188, 2005.

[13] C. Dry, "Procedures developed for self-repair of polymer matrix composite materials," Composite Structures, vol. 35, no. 3, pp. 263-269, 1996.

[14] V. C. Li, Y. M. Lim, and Y. W. Chan, "Feasibility study of a passive smart self-healing cementitious composite," Composites Part B, vol. 29, no. 6, pp. 819-827, 1998.

[15] C. Dry and W. McMillan, "Three-part methylmethacrylate adhesive system as an internal delivery system for smart responsive concrete," Smart Materials and Structures, vol. 5, no. 3, pp. 297-300, 1996.

[16] C. Dry, "Matrix cracking repair and filling using active and passive modes for smart timed release of chemicals from fibers into cement matrices," Smart Materials and Structures, vol. 3, no. 2, pp. 118-123, 1994.
[17] M. Motuku, U. K. Vaidya, and G. M. Janowski, "Parametric studies on self-repairing approaches for resin infused composites subjected to low velocity impact," Smart Materials and Structures, vol. 8, no. 5, pp. 623-638, 1999.

[18] S. M. Bleay, C. B. Loader, V. J. Hawyes, L. Humberstone, and P. T. Curtis, "A smart repair system for polymer matrix composites," Composites Part A, vol. 32, no. 12, pp. 17671776, 2001.

[19] B. Z. Jang, L. C. Chen, L. R. Hwang et al., "The response of fibrous composites to impact loading," Polymer Composites, vol. 11, pp. 144-157, 1990.

[20] R. S. Trask and I. P. Bond, "Biomimetic self-healing of advanced composite structures using hollow glass fibres," Smart Materials and Structures, vol. 15, no. 3, pp. 704-710, 2006.

[21] K. Sanada, I. Yasuda, and Y. Shindo, "Transverse tensile strength of unidirectional fibre-reinforced polymers and self-healing of interfacial debonding," Plastics, Rubber and Composites, vol. 35, no. 2, pp. 67-72, 2006.

[22] M. R. Kessler and S. R. White, "Self-activated healing of delamination damage in woven composites," Composites Part A: Applied Science and Manufacturing, vol. 32, no. 5, pp. 683699, 2001.

[23] K. S. Toohey, N. R. Sottos, J. A. Lewis, J. S. Moore, and S. R. White, "Self-healing materials with microvascular networks," Nature Materials, vol. 6, no. 8, pp. 581-585, 2007.

[24] H. R. Williams, R. S. Trask, and I. P. Bond, "Self-healing composite sandwich structures," Smart Materials and Structures, vol. 16, no. 4, pp. 1198-1207, 2007.

[25] M. Zako and N. Takano, "Intelligent material systems using epoxy particles to repair microcracks and delamination damage in GFRP," Journal of Intelligent Material Systems and Structures, vol. 10, no. 10, pp. 836-841, 1999.

[26] S. A. Hayes, W. Zhang, M. Branthwaite, and F. R. Jones, "Self-healing of damage in fibre-reinforced polymer-matrix composites," Journal of the Royal Society Interface, vol. 4, no. 13, pp. 381-387, 2007.

[27] E. L. Kirkby, J. D. Rule, V. J. Michaud, N. R. Sottos, S. R. White, and J. -A.E. Månson, "Embedded shape-memory alloy wires for improved performance of self-healing polymers," Advanced Functional Materials, vol. 18, no. 15, pp. 2253-2260, 2008.

[28] E. B. Murphy, E. Bolanos, C. Schaffner-Hamann, F. Wudl, S. R. Nutt, and M. L. Auad, "Synthesis and characterization of a single-component thermally remendable polymer network: staudinger and stille revisited," Macromolecules, vol. 41, no. 14, pp. 5203-5209, 2008.

[29] M. W. Keller, S. R. White, and N. R. Sottos, "A self-healing poly(dimethyl siloxane) elastomer," Advanced Functional Materials, vol. 17, no. 14, pp. 2399-2404, 2007.

[30] C. B. Lin, S. Lee, and K. S. Liu, "Methanol-induced crack healing in poly(methyl methacrylate)," Polymer Engineering and Science, vol. 30, no. 21, pp. 1399-1406, 1990.

[31] C.-M. Chung, Y.-S. Roh, S.-Y. Cho, and J.-G. Kim, "Crack healing in polymeric materials via photochemical [2+2] cycloaddition," Chemistry of Materials, vol. 16, no. 21, pp. 3982-3984, 2004.

[32] R. P. Wool and K. M. O'Connor, "A theory of crack healing in polymers," Journal of Applied Physics, vol. 52, no. 10, pp. 5953-5963, 1981.

[33] E. N. Brown, N. R. Sottos, and S. R. White, "Fracture testing of a self-healing polymer composite," Experimental Mechanics, vol. 42, no. 4, pp. 372-379, 2002.

[34] E. N. Brown, S. R. White, and N. R. Sottos, "Retardation and repair of fatigue cracks in a microcapsule toughened epoxy 
composite-part II: in situ self-healing," Composites Science and Technology, vol. 65, no. 15-16, pp. 2474-2480, 2005.

[35] Y. C. Yuan, M. Z. Rong, M. Q. Zhang, and G. C. Yang, "Study of factors related to performance improvement of selfhealing epoxy based on dual encapsulated healant," Polymer, vol. 50, no. 24, pp. 5771-5781, 2009.

[36] X. Liu, X. Sheng, J. K. Lee, and M. R. Kessler, "Synthesis and characterization of melamine- urea-formaldehyde microcapsules containing ENB-based self-healing agents," Macromolecular Materials and Engineering, vol. 294, no. 6-7, pp. 389-395, 2009.

[37] G. Lanzara, Y. Yoon, H. Liu, S. Peng, and W.-I. Lee, "Carbon nanotube reservoirs for self-healing materials," Nanotechnology, vol. 20, no. 33, article 335704, 2009.

[38] D. Y. Wu, S. Meure, and D. Solomon, "Self-healing polymeric materials: a review of recent developments," Progress in Polymer Science, vol. 33, no. 5, pp. 479-522, 2008.

[39] M. J. Hucker, I. P. Bond, S. Haq, S. Bleay, and A. Foreman, "Influence of manufacturing parameters on the tensile strengths of hollow and solid glass fibres," Journal of Materials Science, vol. 37, no. 2, pp. 309-315, 2002.

[40] R. S. Trask, G. J. Williams, and I. P. Bond, "Bioinspired selfhealing of advanced composite structures using hollow glass fibres," Journal of the Royal Society Interface, vol. 4, no. 13, pp. 363-371, 2007.

[41] M. Hucker, I. Bond, A. Foreman, and J. Hudd, "Optimisation of hollow glass fibres and their composites," Advanced Composites Letters, vol. 8, no. 4, pp. 181-189, 1999.

[42] M. Hucker, I. Bond, S. Bleay, and S. Haq, "Experimental evaluation of unidirectional hollow glass fibre/epoxy composites under compressive loading," Composites Part A, vol. 34, no. 10, pp. 927-932, 2003.

[43] G. Williams, R. Trask, and I. Bond, "A self-healing carbon fibre reinforced polymer for aerospace applications," Composites Part A, vol. 38, no. 6, pp. 1525-1532, 2007.

[44] G. J. Williams, I. P. Bond, and R. S. Trask, "Compression after impact assessment of self-healing CFRP," Composites Part A: Applied Science and Manufacturing, vol. 40, no. 9, pp. 13991406, 2009.

[45] J. M. Asua, "Miniemulsion polymerization," Progress in Polymer Science, vol. 27, pp. 1283-1346, 2002.

[46] E. N. Brown, S. R. White, and N. R. Sottos, "Microcapsule induced toughening in a self-healing polymer composite," Journal of Materials Science, vol. 39, no. 5, pp. 1703-1710, 2004.

[47] M. R. Kessler, N. R. Sottos, and S. R. White, "Self-healing structural composite materials," Composites Part A, vol. 34, no. 8, pp. 743-753, 2003.

[48] L. Yuan, G. Z. Liang, J. Q. Xie, L. Li, and J. Guo, "Preparation and characterization of poly(urea-formaldehyde) microcapsules filled with epoxy resins," Polymer, vol. 47 , no. 15, pp. 5338-5349, 2006.

[49] E. N. Brown, S. R. White, and N. R. Sottos, "Retardation and repair of fatigue cracks in a microcapsule toughened epoxy composite_-part I: manual infiltration," Composites Science and Technology, vol. 65, no. 15-16, pp. 2466-2473, 2005.

[50] A. S. Jones, J. D. Rule, J. S. Moore, N. R. Sottos, and S. R. White, "Life extension of self-healing polymers with rapidly growing fatigue cracks," Journal of the Royal Society Interface, vol. 4, no. 13, pp. 395-403, 2007.

[51] S. Cosco, V. Ambrogi, P. Musto, and C. Carfagna, "Urea-formaldehyde microcapsules containing an epoxy resin: influence of reaction parameters on the encapsulation yield," $M a-$ cromolecular Symposia, vol. 234, pp. 184-192, 2006.
[52] L. Yuan, G. Liang, J. Q. Xie, L. Li, and J. Guo, “The permeability and stability of microencapsulated epoxy resins," Journal of Materials Science, vol. 42, no. 12, pp. 4390-4397, 2007.

[53] T. Yin, M. Z. Rong, M. Q. Zhang, and G. C. Yang, "Selfhealing epoxy composites-preparation and effect of the healant consisting of microencapsulated epoxy and latent curing agent," Composites Science and Technology, vol. 67, no. 2, pp. 201-212, 2007.

[54] B. J. Blaiszik, M. M. Caruso, D. A. Mcllroy, J. S. Moore, S. R. White, and N. R. Sottos, "Microcapsules filled with reactive solutions for self-healing materials," Polymer, vol. 50, no. 4, pp. 990-997, 2009.

[55] E. B. Murphy and F. Wudl, "The world of smart healable materials," Progress in Polymer Science, vol. 35, no. 1-2, pp. 223-251, 2010.

[56] M. W. Keller and N. R. Sottos, "Mechanical properties of microcapsules used in a self-healing polymer," Experimental Mechanics, vol. 46, no. 6, pp. 725-733, 2006.

[57] J. D. Rule, N. R. Sottos, and S. R. White, "Effect of microcapsule size on the performance of self-healing polymers," Polymer, vol. 48, no. 12, pp. 3520-3529, 2007.

[58] B. J. Blaiszik, N. R. Sottos, and S. R. White, "Nanocapsules for self-healing materials," Composites Science and Technology, vol. 68, no. 3-4, pp. 978-986, 2008.

[59] E. N. Brown, M. R. Kessler, N. R. Sottos, and S. R. White, "In situ poly(urea-formaldehyde) microencapsulation of dicyclopentadiene," Journal of Microencapsulation, vol. 20, no. 6, pp. 719-730, 2003.

[60] L. Yuan, G. Liang, J. Q. Xie, and S. He, "Synthesis and characterization of microencapsulated dicyclopentadiene with melamine-formaldehyde resins," Colloid and Polymer Science, vol. 285, no. 7, pp. 781-791, 2007.

[61] C. Y. Yan, M. Z. Rong, M. Q. Zhang, J. Chen, G. C. Yang, and X. M. Li, "Self-healing polymeric materials using epox$y /$ mercaptan as the healant," Macromolecules, vol. 41, no. 14, pp. 5197-5202, 2008.

[62] J. Yang, M. W. Keller, J. S. Moore, S. R. White, and N. R. Sottos, "Microencapsulation of isocyanates for self-healing polymers," Macromolecules, vol. 41, no. 24, pp. 9650-9655, 2008.

[63] S. D. Mookhoek, B. J. Blaiszik, H. R. Fischer, N. R. Sottos, S. R. White, and S. Van Der Zwaag, "Peripherally decorated binary microcapsules containing two liquids," Journal of $\mathrm{Ma}$ terials Chemistry, vol. 18, no. 44, pp. 5390-5394, 2008.

[64] M. A. White, "The chemistry behind carbonless copy paper," Journal of Chemical Education, vol. 75, no. 9, pp. 1119-1120, 1998.

[65] C. Andersson, L. Järnström, A. Fogden et al., "Preparation and incorporation of microcapsules in functional coatings for self-healing of packaging board," Packaging Technology and Science, vol. 22, no. 5, pp. 275-291, 2009.

[66] Z. G. Wei, R. Sandström, and S. Miyazaki, "Review: shape memory materials and hybrid composites for smart systems," Journal of Materials Science, vol. 33, no. 15, pp. 3763-3783, 1983.

[67] J. Schrooten, V. Michaud, J. Parthenios et al., "Progress on composites with embedded shape memory alloy wires," $M a-$ terials Transactions, vol. 43, no. 5, pp. 961-973, 2002.

[68] K. A. Tsoi, J. Schrooten, and R. Stalmans, "Part I. Thermomechanical characteristics of shape memory alloys," Materials Science and Engineering A, vol. 368, no. 1-2, pp. 286-298, 2004.

[69] C. A. Rogers, C. Liang, and C. R. Fuller, "Modeling of shape memory alloy hybrid composites for structural acoustic 
control," Journal of the Acoustical Society of America, vol. 89, no. 1, pp. 210-220, 1991.

[70] A. A. Baker, R. Jones, and R. J. Callinan, "Damage tolerance of graphite/epoxy composites," Composite Structures, vol. 4, no. 1, pp. 15-44, 1985.

[71] J. C. Prichard and P. J. Hogg, "The role of impact damage in post-impact compression testing," Composites, vol. 21, no. 6, pp. 503-511, 1990.

[72] F. J. Guild, P. J. Hogg, and J. C. Prichard, "A model for the reduction in compression strength of continuous fibre composites after impact damage," Composites, vol. 24, no. 4, pp. 333-339, 1993.

[73] Y. Xiong, C. Poon, P. V. Straznicky, and H. Vietinghoff, "A prediction method for the compressive strength of impact damaged composite laminates," Composite Structures, vol. 30, no. 4, pp. 357-367, 1995.

[74] A. S. Chen, D. P. Almond, and B. Harris, "Impact damage growth in composites under fatigue conditions monitored by acoustography," International Journal of Fatigue, vol. 24, no. 2-4, pp. 257-261, 2002.

[75] M. Mitrovic, H. T. Hahn, G. P. Carman, and P. Shyprykevich, "Effect of loading parameters on the fatigue behavior of impact damaged composite laminates," Composites Science and Technology, vol. 59, no. 14, pp. 2059-2078, 1999.

[76] S. H. Myhre and J. D. Labor, "Repair of advanced composite structures," Journal of Aircraft, vol. 18, no. 7, pp. 546-552, 1981.

[77] R. B. Heslehurst, "Challenges in the repair of composite structures-part I," SAMPE Journal, vol. 33, no. 5, pp. 11-16, 1997.

[78] R. B. Heslehurst, "Challenges in the repair of composite structures-part II," SAMPE Journal, vol. 33, no. 6, pp. 16-21, 1997.

[79] L. Dorworth and G. Gardiner, "Repair of composite structures-a review," Journal of Advanced Materials, vol. 39, no. 4, pp. 3-13, 2007.

[80] A. J. Patel, N. R. Sottos, E. D. Wetzel, and S. R. White, "Autonomic healing of low-velocity impact damage in fiberreinforced composites," Composites Part A, vol. 41, no. 3, pp. 360-368, 2010.

[81] S. J. Kalista Jr., T. C. Ward, and Z. Oyetunji, "Self-healing of poly(ethylene-co-methacrylic acid) copolymers following projectile puncture," Mechanics of Advanced Materials and Structures, vol. 14, no. 5, pp. 391-397, 2007.

[82] B. A. Beiermann, M. W. Keller, and N. R. Sottos, "Self-healing flexible laminates for resealing of puncture damage," Smart Materials and Structures, vol. 18, no. 8, article 085001, 2009.

[83] E. N. Brown, M. R. Kessler, N. R. Sottos, and S. R. White, "In situ poly(urea-formaldehyde) microencapsulation of dicyclopentadiene," Journal of Microencapsulation, vol. 20, no. 6, pp. 719-730, 2003.

[84] A. S. Jones, J. D. Rule, J. S. Moore, S. R. White, and N. R. Sottos, "Catalyst morphology and dissolution kinetics of selfhealing polymers," Chemistry of Materials, vol. 18, no. 5, pp. 1312-1317, 2006.

[85] J. D. Rule, E. N. Brown, N. R. Sottos, S. R. White, and J. S. Moore, "Wax-protected catalyst microspheres for efficient self-healing materials," Advanced Materials, vol. 17, no. 2, pp. 205-208, 2005.

[86] J. K. Lee, S. J. Hong, X. Liu, and S. H. Yoon, "Characterization of dicyclopentadiene and 5-ethylidene-2-norbornene as selfhealing agents for polymer composite and its microcapsules," Macromolecular Research, vol. 12, no. 5, pp. 478-483, 2004.
[87] X. Liu, J. K. Lee, S. H. Yoon, and M. R. Kessler, "Characterization of diene monomers as healing agents for autonomic damage repair," Journal of Applied Polymer Science, vol. 101, no. 3, pp. 1266-1272, 2006.

[88] M. R. Kessler and S. R. White, "Cure kinetics of the ringopening metathesis polymerization of dicyclopentadiene," Journal of Polymer Science, Part A: Polymer Chemistry, vol. 40, no. 14, pp. 2373-2383, 2002.

[89] M. Chipara, J. Zaleski, B. Dragnea, E. Shansky, T. Onuta, and M. D. Chipara, "Self-Healing polymers for space applications," in Proceedings of the 47th AIAA/ASME/ASCE/AHS/ASC Structures, Structural Dynamics and Materials Conference, pp. 4371-4379, May 2006.

[90] J. D. Rule and J. S. Moore, "ROMP reactivity of endo- and exo-dicyclopentadiene," Macromolecules, vol. 35, no. 21, pp. 7878-7882, 2002.

[91] S. H. Cho, H. M. Andersson, S. R. White, N. R. Sottos, and P. V. Braun, "Polydiniethylsiloxane-based self-healing materials," Advanced Materials, vol. 18, no. 8, pp. 997-1000, 2006.

[92] L. Yuan, G. Z. Liang, J. Q. Xie, J. Guo, and L. Li, “Thermal stability of microencapsulated epoxy resins with poly(ureaformaldehyde)," Polymer Degradation and Stability, vol. 91, no. 10, pp. 2300-2306, 2006.

[93] R. O. Ritchie, "Mechanisms of fatigue crack propagation in metals, ceramics and composites-role of crack tip shielding," Materials Science and Engineering, vol. 103, no. 1, pp. 15-28, 1988.

[94] C. W. Bielawski and R. H. Grubbs, "Living ring-opening metathesis polymerization," Progress in Polymer Science, vol. 32, no. 1, pp. 1-29, 2007.

[95] J. C. Mol, "Industrial applications of olefin metathesis," Journal of Molecular Catalysis A: Chemical, vol. 213, no. 1, pp. 3945, 2004.

[96] Y. S. Yang, E. Lafontaine, and B. Mortaigne, "Curing study of dicyclopentadiene resin and effect of elastomer on its polymer network," Polymer, vol. 38, no. 5, pp. 1121-1130, 1997.

[97] G. B. Shah, "Effect of length of ligand in organotin compounds on their catalytic activity for the polycondensation of silicone," Journal of Applied Polymer Science, vol. 70, no. 11, pp. 2235-2239, 1998.

[98] F. W. van der Weij, "The action of tin compounds in condensation-type RTV silicone rubbers," Macromolecular Chemistry, vol. 181, pp. 2541-2548, 1980.

[99] G. B. West, J. H. Brown, and B. J. Enquist, "A general model for the structure and allometry of plant vascular systems," Nature, vol. 400, no. 6745, pp. 664-667, 1999.

[100] A. Roth-Nebelsick, D. Uhl, V. Mosbrugger, and H. Kerp, "Evolution and function of leaf venation architecture: a review," Annals of Botany, vol. 87, no. 5, pp. 553-566, 2001.

[101] N. M. Holbrook and M. A. Zwieniecki, Vascular Transport in Plants, Elsevier, Burlington, Mass, USA, 2005.

[102] L. Sack and K. Frole, "Leaf structural diversity is related to hydraulic capacity in tropical rain forest trees," Ecology, vol. 87, no. 2, pp. 483-491, 2006.

[103] G. B. West, J. H. Brown, and B. J. Enquist, "A general model for the origin of allometric scaling laws in biology," Science, vol. 276, no. 5309, pp. 122-126, 1997.

[104] B. Sapoval, M. Filoche, and E. R. Weibel, "Smaller is betterbut not too small: a physical scale for the design of the mammalian pulmonary acinus," Proceedings of the National Academy of Sciences of the United States of America, vol. 99, no. 16, pp. 10411-10416, 2002. 
[105] R. K. Jain, "Normalization of tumor vasculature: an emerging concept in antiangiogenic therapy," Science, vol. 307, no. 5706, pp. 58-62, 2005.

[106] A. D. Stroock and M. Cabodi, "Microfluidic biomaterials," MRS Bulletin, vol. 31, no. 2, pp. 114-119, 2006.

[107] N. W. Choi, M. Cabodi, B. Held, J. P. Gleghorn, L. J. Bonassar, and A. D. Stroock, "Microfluidic scaffolds for tissue engineering," Nature Materials, vol. 6, no. 11, pp. 908-915, 2007.

[108] M. K. Runyon, B. L. Johnson-Kerner, C. J. Kastrup, T. G. van $\mathrm{Ha}$, and R. F. Ismagilov, "Propagation of blood clotting in the complex biochemical network of hemostasis is described by a simple mechanism," Journal of the American Chemical Society, vol. 129, no. 22, pp. 7014-7015, 2007.

[109] J. M. Higgins, D. T. Eddington, S. N. Bhatia, and L. Mahadevan, "Sickle cell vasoocclusion and rescue in a microfluidic device," Proceedings of the National Academy of Sciences of the United States of America, vol. 104, no. 51, pp. 20496-20500, 2007.

[110] D. Lim, Y. Kamotani, B. Cho, J. Mazumder, and S. Takayama, "Fabrication of microfluidic mixers and artificial vasculatures using a high-brightness diode-pumped Nd:YAG laser direct write method," Lab on a Chip, vol. 3, no. 4, pp. 318323, 2003.

[111] D. H. Kam and J. Mazumder, "Three-dimensional biomimetic microchannel network by laser direct writing," Journal of Laser Applications, vol. 20, no. 3, pp. 185-191, 2008.

[112] D. Therriault, S. R. White, and J. A. Lewis, "Chaotic mixing in three-dimensional microvascular networks fabricated by direfct-write assembly," Nature Materials, vol. 2, no. 4, pp. 265-271, 2003.

[113] K. S. Toohey, C. J. Hansen, J. A. Lewis, S. R. White, and N. R. Sottos, "Delivery of two-part self-healing chemistry via microvascular networks," Advanced Functional Materials, vol. 19, no. 9, pp. 1399-1405, 2009.

[114] H. R. Williams, R. S. Trask, and I. P. Bond, "Self-healing sandwich panels: restoration of compressive strength after impact," Composites Science and Technology, vol. 68, no. 1516, pp. 3171-3177, 2008.

[115] M. M. Caruso, D. A. Delafuente, V. Ho, N. R. Sottos, J. S. Moore, and S. R. White, "Solvent-promoted self-healing epoxy materials," Macromolecules, vol. 40, no. 25, pp. 8830-8832, 2007.

[116] D. G. Shchukin and H. Möhwald, "Self-repairing coatings containing active nanoreservoirs," Small, vol. 3, no. 6, pp. 926-943, 2007.

[117] X. X. Chen, M. A. Dam, K. Ono et al., "A thermally re-mendable cross-linked polymeric material," Science, vol. 295, no. 5560, pp. 1698-1702, 2002.

[118] X. X. Chen, F. Wudl, A. K. Mal, H. B. Shen, and S. R. Nutt, "New thermally remendable highly cross-linked polymeric materials," Macromolecules, vol. 36, no. 6, pp. 1802-1807, 2003.

[119] F. R. Kersey, D. M. Loveless, and S. L. Craig, "A hybrid polymer gel with controlled rates of cross-link rupture and selfrepair," Journal of the Royal Society Interface, vol. 4, no. 13, pp. 373-380, 2007.

[120] P. Cordier, F. Tournilhac, C. Soulié-Ziakovic, and L. Leibler, "Self-healing and thermoreversible rubber from supramolecular assembly," Nature, vol. 451, no. 7181, pp. 977-980, 2008.

[121] J. Y. Lee, G. A. Buxton, and A. C. Balazs, "Using nanoparticles to create self-healing composites," Journal of Chemical Physics, vol. 121, no. 11, pp. 5531-5540, 2004.
[122] S. Gupta, Q. L. Zhang, T. Emrick, A. C. Balazs, and T. P. Russell, "Entropy-driven segregation of nanoparticles to cracks in multilayered composite polymer structures," Nature Materials, vol. 5, no. 3, pp. 229-233, 2006.

[123] R. Verberg, A. T. Dale, P. Kumar, A. Alexeev, and A. C. Balazs, "Healing substrates with mobile, particle-filled microcapsules: designing a "repair and go" system," Journal of the Royal Society Interface, vol. 4, no. 13, pp. 349-357, 2007.

[124] P. Krishnamurthy and E. B. Coughlin, "Norbornene polymerizations using neutral nickel salicylaldiminato catalysts with borane activators," American Chemical Society, Division of Polymeric Materials: Science and Engineering, PMSE Preprints, vol. 91, pp. 966-967, 2004.

[125] S. J. Kalista and T. C. Ward, "Thermal characteristics of the self-healing response in poly(ethylene-co-methacrylic acid) copolymers," Journal of the Royal Society Interface, vol. 4, no. 13, pp. 405-411, 2007.

[126] D. V. Andreeva, D. Fix, H. Möhwald, and D. G. Shchukin, "Self-healing anticorrosion coatings based on $\mathrm{pH}$-sensitive polyelectrolyte/inhibitor sandwichlike nanostructures," Advanced Materials, vol. 20, no. 14, pp. 2789-2794, 2008.

[127] G. H. Koch, M. P. Brongers, N. G. Thompson et al., "Corrosion costs and preventive strategies in the United States," Tech. Rep. FHWA-RD-01-156, U. S. Department of Transportation, Federal Highway Administration, Washington, DC, USA, 2001.

[128] S. H. Cho, S. R. White, and P. V. Braun, "Self-healing polymer coatings," Advanced Materials, vol. 21, no. 6, pp. 645-649, 2009.

[129] K. Aramaki, "Self-healing mechanism of an organosiloxane polymer film containing sodium silicate and cerium (III) nitrate for corrosion of scratched zinc surface in $0.5 \mathrm{M} \mathrm{NaCl}$," Corrosion Science, vol. 44, no. 7, pp. 1621-1632, 2002.

[130] K. Aramaki, "XPS and EPMA studies on self-healing mechanism of a protective film composed of hydrated cerium(III) oxide and sodium phosphate on zinc," Corrosion Science, vol. 45, no. 1, pp. 199-210, 2003.

[131] K. Aramaki, "Corrosion prevention of passivated iron in 0.1 $\mathrm{M} \mathrm{NaCl}$ by coverage with an ultrathin polymer coating and healing treatment in $0.1 \mathrm{M} \mathrm{NaNO}_{3}$," Corrosion Science, vol. 52, no. 4, pp. 1464-1471, 2010.

[132] K. Aramaki and T. Shimura, "An ultrathin polymer coating of carboxylate self-assembled monolayer adsorbed on passivated iron to prevent iron corrosion in $0.1 \mathrm{M} \mathrm{Na}_{2} \mathrm{SO}_{4}$," Corrosion Science, vol. 52, no. 1, pp. 1-6, 2010.

[133] A. Kumar, L. D. Stephenson, and J. N. Murray, "Self-healing coatings for steel," Progress in Organic Coatings, vol. 55, no. 3, pp. 244-253, 2006.

[134] J. N. Murray, L. D. Stephenson, and A. Kumar, "Electrochemical and physical evaluations of coil coatings on metal-coated steels for roofing applications," Progress in Organic Coatings, vol. 47, no. 2, pp. 136-146, 2003.

[135] F. Pearlstein and V. S. Agarwala, "Chemical conversion coatings for aluminum using trivalent chromium solutions," in Proceedings of the AESF Conference on Symposium on the Search for Environmentally Safer Deposition Processes for Electronics, pp. 112-123, 1993.

[136] N. K. Mehta and M. N. Bogere, "Environmental studies of smart/self-healing coating system for steel," Progress in Organic Coatings, vol. 64, no. 4, pp. 419-428, 2009.

[137] R. J. Varley and S. van der Zwaag, "Towards an understanding of thermally activated self-healing of an ionomer system 
during ballistic penetration," Acta Materialia, vol. 56, no. 19, pp. 5737-5750, 2008.

[138] S. van der Zwaag, "An introduction to material design principles: damage prevention versus damage management SelfHealing Materials," in An Alternative Approach to 20 Centuries of Materials Science, S. van der Zwaag, Ed., Springer, Dordrecht, The Netherlands, 2007.

[139] H. H. Kausch and K. Jud, "Molecular aspects of crack formation and healthy in glassy polymers," Plastics and Rubber Processing and Applications, vol. 2, pp. 265-268, 1982.

[140] H. H. Kausch, "The nature of defects and their role in large deformation and fracture of engineering thermoplastics," Pure and Applied Chemistry, vol. 55, no. 5, pp. 833-844, 1983.

[141] R. P. Sijbesma, F. H. Beijer, L. Brunsveld et al., "Reversible polymers formed from self-complementary monomers using quadruple hydrogen bonding," Science, vol. 278, no. 5343, pp. 1601-1604, 1997.

[142] J. N. Coleman, U. Khan, and Y. K. Gun'ko, "Mechanical reinforcement of polymers using carbon nanotubes," Advanced Materials, vol. 18, no. 6, pp. 689-706, 2006.

[143] C. Liu, Y. Y. Fan, M. Liu, H. T. Cong, H. M. Cheng, and M. S. Dresselhaus, "Hydrogen storage in single-walled carbon nanotubes at room temperature," Science, vol. 286, no. 5442, pp. 1127-1129, 1999.

[144] C. Guerret-Plecourt, Y. Le Bouar, A. Loiseau, and H. Pascard, "Relation between metal electronic structure and morphology of metal compounds inside carbon nanotubes," $\mathrm{Na}$ ture, vol. 372, no. 6508, pp. 761-765, 1994.

[145] Y. Xue and M. Chen, "Transport of molecules through carbon nanotube channels in aqueous environment: a molecular dynamics study," Materials Research Society Symposium Proceedings, vol. 899E, p. 0899-N03-08.1, 2006.

[146] B. Ni, S. B. Sinnott, P. T. Mikulski, and J. A. Harrison, "Compression of carbon nanotubes filled with $\mathrm{C}_{60}, \mathrm{CH}_{4}$, or Ne: predictions from molecular dynamics simulations," Physical Review Letters, vol. 88, no. 20, pp. 2055051-2055054, 2002.

[147] H. Gao, Y. Kong, D. Cui, and C. S. Ozkan, "Spontaneous insertion of DNA oligonucleotides into carbon nanotubes," Nano Letters, vol. 3, no. 4, pp. 471-473, 2003. 

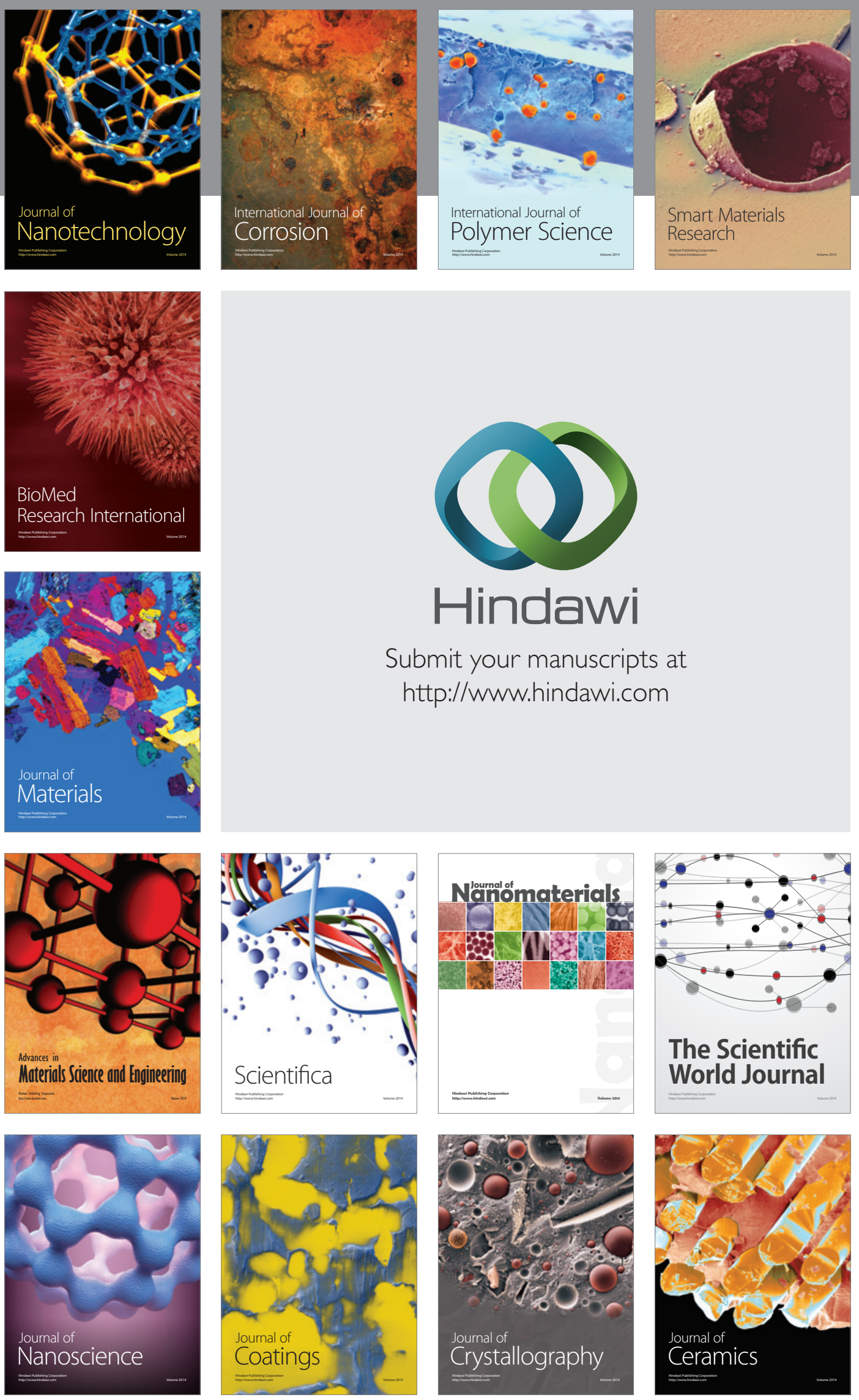

The Scientific World Journal

Submit your manuscripts at

http://www.hindawi.com

\section{World Journal}

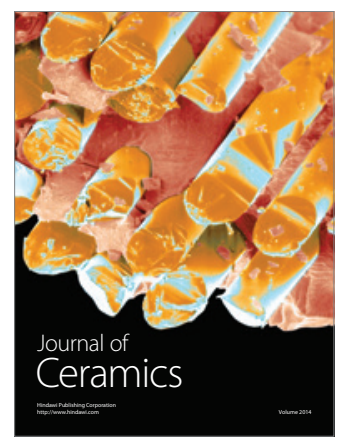

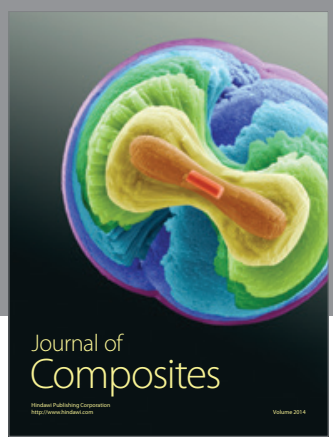
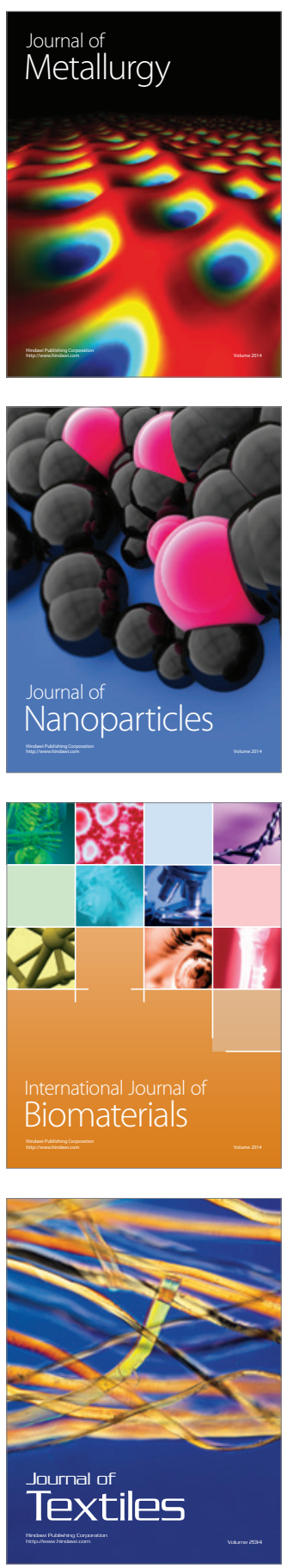